\title{
Plan de Negocios para la Exportación de Máquinas para la fabricación de Pastas Frescas Marca D’alessio.
}

Trabajo Científico libre para la obtención del grado de Magister en Marketing Internacional de la Escuela de Postgrado de Marketing Internacional-Facultad de Ciencias Económicas

- Universidad Nacional de La Plata -

Profesor Director de Tesis:

Prof. Ing. Enzo Campana
Presentado por:

Tomás Pablo Guerrino

421 y 133 № 3208 Villa Elisa

(1894) La Plata 


\section{PRÓLOGO Y AGRADECIMIENTOS}

Antes que nada, quiero agradecer a la EPMI, a todos sus directivos y profesores.

En especial a la Secretaria Académica Cdra. Liesel Bischoff que durante toda la Maestría nos ha brindado todo de sí.

Al Prof. Ing. Enzo Campana por motivarme en el desarrollo de esta Tesis.

A mi esposa y mis hijos que me han apoyado desde el comienzo hasta el final.

A mi padre que si estuviera se sentiría muy orgulloso.

A mi madre por ser como es.

Al analizar los posibles temas para ser presentados en este trabajo de investigación consideré oportuno aplicar los conocimientos académicos obtenidos y llevarlos a la práctica sobre un caso real donde una empresa Pyme Argentina quiere incursionar en negocios internacionales y por diferentes motivos no ha podido establecer un plan de negocios para la exportación de los productos que fabrica. 
1 ALCANCE, OBJETIVOS Y METODOLOGÍA 6

2 PRESENTACIÓN DE LA EMPRESA

$\begin{array}{ll}2.1 \text { Antecedentes } & 7\end{array}$

2.2. Valores 8

2.2.1 Visión 8

2.2.2 Misión 8

2.3 Escenario de la empresa $\quad 8$

2.3.1 Instalaciones 8

2.3.2 Estructura organizacional 9

$\begin{array}{ll}\text { 2.3.3 Nivel de internacionalización alcanzado } & 10\end{array}$

$\begin{array}{ll}\text { 2.4 Portfolio de Productos } & 11\end{array}$

3 PLAN DE NEGOCIOS $\quad 19$

$\begin{array}{ll}3.1 \text { Características del producto } & 19\end{array}$

$\begin{array}{ll}3.2 \text { Clasificación del producto en el N.C.M } & 19\end{array}$

3.2.1 Reglamentación y normas para la exportación 20

$\begin{array}{ll}\text { 3.2.2 Requisitos aduaneros y aranceles de exportación } & 20\end{array}$

3.2.3 Mercado único y libre de cambios $\quad 21$

3.2.4 Embalaje para exportación 21

$\begin{array}{ll}\text { 3.2.5 Plan financiero } & 21\end{array}$

3.3 Fortalezas y debilidades $\quad 22$

3.3.1 Fortalezas 22

3.3.2 Debilidades 22

$\begin{array}{ll}\text { 3.3.3 Oportunidades } & 22\end{array}$ 
4 IDENTIFICACION DE LOS MERCADOS POTENCIALES 23

$\begin{array}{ll}4.1 \text { Uruguay } & 25\end{array}$

4.1.1 Aspectos generales $\quad 25$

4.1.2 Economía y negocios 26

4.1.3 Principales indicadores económicos del Uruguay 27

4.1.4 Balanza comercial Uruguay-Argentina 27

4.1.5 Infraestructura, transporte y comunicaciones 29

4.1.6 Transporte carretero $\quad 30$

$\begin{array}{ll}\text { 4.1.7 Transporte ferroviario } & 30\end{array}$

4.1.8 Transporte fluvial y marítimo 31

4.1.9 Transporte aéreo 31

4.1.10 Normas legales para el ingreso de productos en Uruguay 32

4.1.11 Costo de introducción de las mercaderías importadas 33

4.1.12 Valoración aduanera 33

4.1.13 Impuestos internos $\quad 34$

4.1.14 Tasas de servicios 34

4.1.15 Costos portuarios $\quad 35$

4.2 Mercado Meta 36

4.2.1 Características del mercado de pastas 36

4.2.2 Canales de distribución $\quad 40$

5 ESQUEMA DE IMPLEMENTACIÓN DEL PLAN 42

5.1 Definición del precio de exportación 42

5.2 Aspectos logísticos $\quad 44$

5.3 Promoción 44

5.4 Resultado económico proyectado $\quad 45$ 
6 CONCLUSIONES

8 OTRAS FUENTES 48

9 ANEXOS 50

Índice de Anexos

Anexo 1 Distribución poblacional del Uruguay 50

Anexo 2 Consumo de pasta per cápita por país en $2011(\mathrm{~kg})$

Anexo 3 Modelo de contrato de agente de ventas 52

Anexo 4 Costos Internos en Uruguay 54

Índice de Cuadros

Cuadro 1 Clasificación PyME $\quad 8$

Cuadro 2 Principales proyecciones económicas 27

Cuadro 3 Sector externo $\quad 27$

Cuadro 4 Intercambio comercial entre Uruguay -Argentina 29

Cuadro 5 Tasa por servicios extraordinarios $\quad 35$

Cuadro 6 Determinación del precio de exportación Prensa Super Lujo $\quad 43$

Cuadro 7 Cálculo flete vía aérea Buenos Aires - Montevideo 44

Cuadro 8 Proyección de resultados $\quad 45$

Índice de Gráficos

Gráfico 1 Exportaciones uruguayas de bienes hacia Argentina 28

Gráfico 2 Importaciones uruguayas desde Argentina 29

Índice de Imágenes

Imagen 1 Fusilera 2 prensa para fideos $\quad 12$

Imagen 2 Fusilera standard prensa para fideos $\quad 13$

Imagen 3 Nueva fusilera super lujo $\quad 14$

Imagen 4 Máquina combinada $\quad 15$

Imagen 5 Ralladora o picadora individual 16

Imagen 6 Amasadora auxiliar $\quad 17$

$\begin{array}{ll}\text { Imagen } 7 \text { Amasadora térmica } & 18\end{array}$ 


\section{ALCANCE, OBJETIVOS Y METODOLOGÍA}

El presente trabajo tiene el objeto de desarrollar un plan de negocios para la exportación de las máquinas que fabrica la empresa Sucesores de Pedro D’alessio S.R.L.

Incursionarla en una etapa experimental de exportación donde adquiera experiencia y pueda consolidar sus exportaciones en forma continua.

Para llevarlo a cabo analizaremos las competencias de la empresa a los efectos de verificar alternativas de solución para la situación actual de empresa.

\subsection{Objetivos}

1.2 Desarrollar el Plan de Negocios de exportación.

1.3 Evaluar y realizar un diagnóstico del escenario de la empresa.

1.4 Identificar los mercados potenciales.

1.5 Definir la implementación del plan de negocios y plazos para llevarlo a cabo.

1.6 Analizar las barreras de ingreso y el marco legal del Mercado destino.

1.7 Definir el precio de exportación

1.8 Determinar los aspectos logísticos de exportación

1.9 Comercialización

1.10 Análisis económico

1.11 Conclusiones

2 Metodología

Se realizará la investigación en forma vivencial de campo analizando variables cualitativas y cuantitativas.

Las herramientas a ser utilizadas:

Entrevistas en profundidad a los dueños y empleados.

Observación del clima y la cultura empresarial.

Cuantitativas:

Se realizará un análisis económico para definir precio de exportación, márgenes de utilidad y resultado.

Búsqueda en internet de información primaria.

Bibliografía de consulta. 


\section{PRESENTACION DE LA EMPRESA}

\subsection{Antecedentes}

D'alessio es una empresa familiar que fabrica máquinas y accesorios para la elaboración de pastas frescas. Su historia en el sector comienza hace 50 años y hoy los sucesores de Pedro D'alessio continúan su trayectoria certificando la calidad de sus productos.Si bien la empresa ha realizado exportaciones ocasionales de carácter pasiva no ha generado ninguna estrategia proactiva para internacionalizarse por diferentes temores que ameritan una revisión del plan de negocios.

Pedro D'alessio fundador de la empresa comenzó su trayectoria trabajando como técnico en la antigua fábrica de máquinas Cerrini .Su espíritu emprendedor hizo llevarlo a comprar una propiedad en la Ciudad de Buenos Aires con el objetivo de establecer su propia fábrica de máquinas para la elaboración de pastas frescas. La empresa se constituyó formalmente en el año 1984,donde se establece el contrato social de la misma bajo la actividad principal "Fabricación de maquinaria para la elaboración de alimentos, bebidas y tabaco , su denominación Sucesores de Pedro D'alessio S.R.L con C.U.I.T 30-50484751-5 .Está localizada en la Ciudad de Buenos Aires, en la calle Camarones 4851/53, barrio de de Villa Luro Tel:005411-4639-0005 / 4567-5215 CP (C1407FNF) C.A.B.A donde se encuentra la fábrica, el depósito y un pequeño show room donde exhibe sus máquinas. En la actualidad siendo una empresa industrial que factura (entre $\$ 1.800 .000$ y $\$$ 10.300.000) es categorizada como una Pequeña Empresa de acuerdo a la clasificación establecida en la Resolución № 21 del 2010 de la Leyes 24.467 y 25.300 ambas de la Ex Secretaria de la Pequeña y Mediana Empresa ${ }^{1}$.

\footnotetext{
${ }^{1}$ Secretaría de la Pequeña y Mediana Empresa y Desarrollo Regional http://www.sepyme.gob.ar
} 
Cuadro 1 Clasificación Pyme

\begin{tabular}{|c|c|c|c|c|c|}
\hline \multicolumn{6}{|c|}{ SECTOR } \\
\hline TAMAÑO & Agropecuario & Industria y Minería & Comercio & Servicios & Construcción \\
\hline $\begin{array}{l}\text { Micro } \\
\text { Empresa }\end{array}$ & 610.000 & 1.800 .000 & 2.400 .000 & 590.000 & 760.000 \\
\hline $\begin{array}{l}\text { Pequeña } \\
\text { Empresa }\end{array}$ & 4.100 .000 & 10.300 .000 & 14.000 .000 & 4.300 .000 & 4.800 .000 \\
\hline $\begin{array}{l}\text { Mediana } \\
\text { Empresa }\end{array}$ & 24.100 .000 & 82.200 .000 & 111.900 .000 & 28.300 .000 & 37.700 .000 \\
\hline
\end{tabular}

Fuente: Secretaría de la Pequeña y Mediana Empresa y Desarrollo Regional

\subsection{Valores}

\subsubsection{Visión}

Ser líderes regionales en la producción de máquinas y accesorios para la industria de pastas frescas.

\subsubsection{Misión}

Producir máquinas y accesorios para la elaboración de pastas frescas comprometiéndonos con el desarrollo tecnológico y la calidad puesta al servicio de la industria para brindar máximos resultados y mínimo mantenimiento.

Su eslogan es:"Cuando usted elige D'alessio, más que por una máquina se está decidiendo por la calidad probada a través del tiempo en la elaboración de pastas frescas".

\subsection{Escenario de la Empresa}

\subsubsection{Instalaciones}

D’alessio dispone de una línea de producción compuesta de cuatro tornos, una fresadora, dos laminadores y un pantógrafo .La misma está dispuesta en un espacio edilicio de $80 \mathrm{~m} 2$, cuenta con un depósito secundario de $50 \mathrm{~m} 2$ utilizado para almacenar los insumos productivos y productos terminados. La oficina comercial es de $20 \mathrm{~m} 2$ y se utiliza además como show-room .

La línea de producción es por procesos .De acuerdo a la prioridad de cada cliente se establece un criterio de orden de trabajo sin tener una política de producción y abastecimiento claramente definida. 
La capacidad instalada permite producir una máquina en forma mensual con posibilidad de ser ampliada .Los plazos de entrega son de 90 días a partir de la orden de compra y el pago del $50 \%$ del valor de la misma en forma anticipada.

A partir de la compra de un centro de mecanizado los tiempos de entrega se reducirán a la mitad ,lo que le permitirá producir dos máquinas adicionales mensuales y lograr un acabado de producto de mayor calidad, con el objetivo de internacionalizar la empresa y adecuar su producción para atender mercados regionales. En lo que respecta a los sistemas de información ,no dispone de ningún sistema operativo para el control de la información ni realiza estudios de mercado para vigilar el accionar de la competencia .

Si bien la empresa utiliza materias primas provenientes de empresas nacionales de primer nivel que certifican con normas de calidad ISO 9001, no ha incursionado aún en certificar sus productos bajo esas normas.

Dentro del plan de mejoras se atenderán dichos aspectos a los efectos de poder controlar los procesos y sumarle valor agregado a su producto terminado o bien cumplir con exigencias de ciertos mercados internacionales.

\subsubsection{Estructura organizacional}

La estructura organizacional de la empresa es de bajo reconocimiento formal. ${ }^{2}$ Actualmente la empresa es dirigida por sus socios gerentes Susana D'alessio y Martín lazurlo quienes se reparten funciones en el management de la organización: Susana se ocupa de los aspectos administrativos y facturación. Martín de las ventas domésticas e internacionales y el departamento de producción. Además cuentan con el apoyo de un staff conformado por un estudio jurídico contable, realizando las liquidaciones de haberes, aspectos vinculados a temas impositivos y jurídicos.

La mano de obra es especializada en la industria metalúrgica, cuenta con seis operarios técnicos y su labor es específica, cada uno de ellos maneja una máquina, y son coordinados y supervisados por Martín lazurlo.

\footnotetext{
${ }^{2}$ Arese,Héctor Felix, Introducción al Comercio Exterior, Grupo Editorial Norma Esta modalidad se da principalmente en las empresas que comienzan a vender sus productos como extensión de actividades y establecen un primer departamento de exportación. Es decir que atendiendo a los diseños señalados la estructura con bajo reconocimiento formal tendrá un esquema en el cual el departamento de exportación será un apéndice menor en la empresa. 
El horario de trabajo es de 8.00 a 18.00 hs con un receso de 1 hora para almorzar.

Cada uno de los empleados es un eslabón fundamental para el cumplimiento de las tareas productivas.

En el siguiente organigrama se describen las áreas que conforman la estructura organizacional.

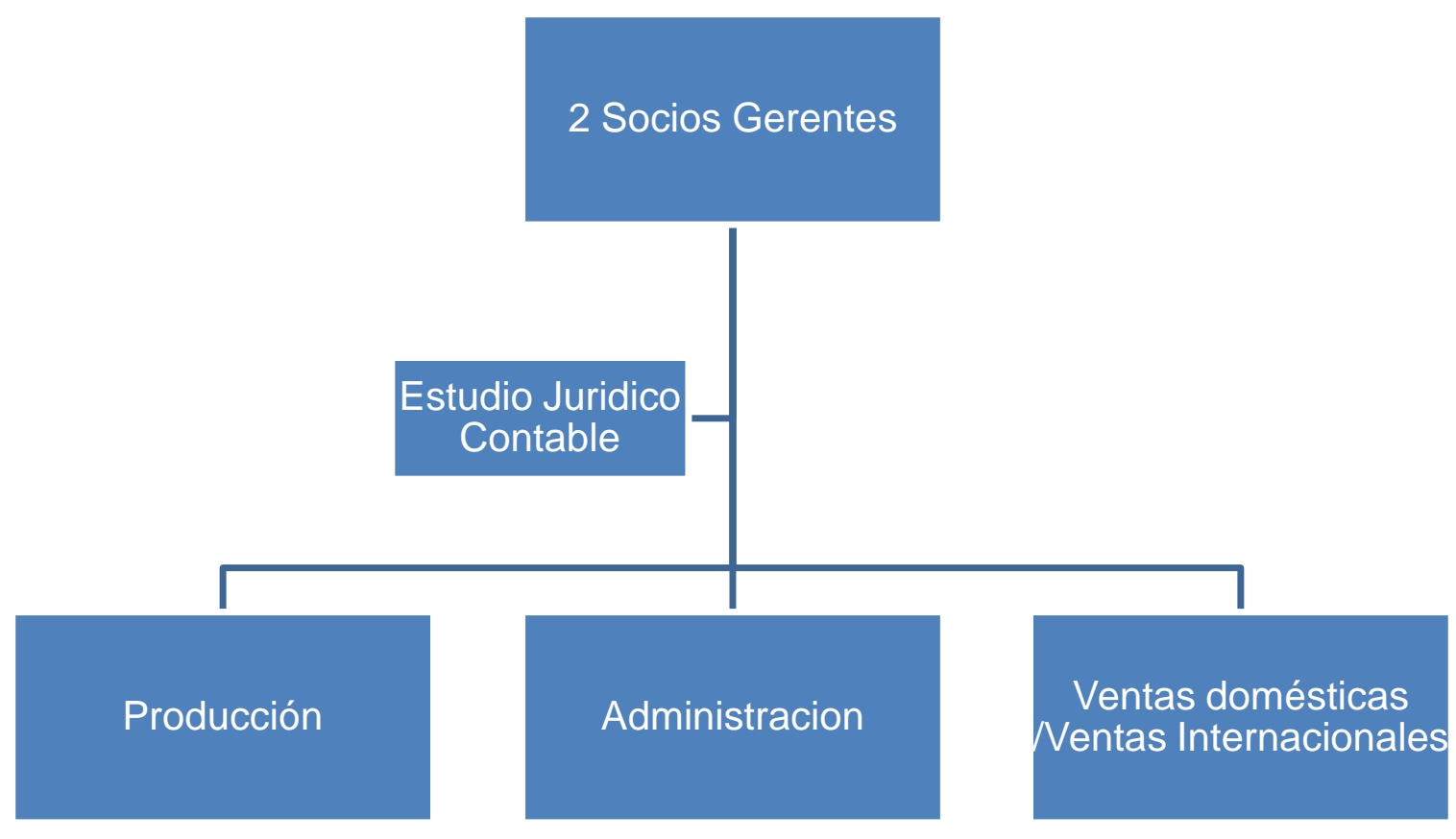

\subsubsection{Nivel de internacionalización alcanzado}

D’alessio, hasta el momento no ha desarrollado ninguna estrategia de exportación por diferentes causas que inciden en su internalización, una de ellas es por falta de conciencia exportadora y una actitud pasiva frente a los negocios internacionales.

Ante las entrevistas realizadas a los socios y a su personal técnico a la hora de responder particularmente sobre este tema contestaron que las exportaciones realizadas fueron generadas por pedidos puntuales del exterior.

La visión de los socios en este momento es llevar a cabo un plan de negocios de exportación que sea en forma gradual a los efectos de generar una retroalimentación dentro de la empresa según las distintas experiencias que se van desarrollando en los mercados externos. 
La capacidad de aprendizaje que genera esta actitud y las decisiones basadas en ella, permitirán que la conciencia exportadora se vaya auto impulsando a lo largo del tiempo.

También se irá incrementando de manera progresiva, el grado de dificultad de los mercados accedidos (desde los más simples hacia los más complejos).

Esto implica también que la empresa deberá realizar una creciente asignación de recursos monetarios, financieros, productivos y humanos hacia los mercados internacionales a medida que se vaya afianzando en los mismos. ${ }^{3}$

\subsection{Portfolio de Productos}

Los productos que fabrica la empresa se comercializan con la marca D'alessio, sus principales clientes son fábricas de pastas frescas, supermercados y restaurantes.

En la actualidad la empresa es líder en la fabricación de las máquinas para elaborar pastas frescas, prensas para fideos (Fusileras y Máquinas combinadas). Hace más de 10 años D'alessio celebró un acuerdo con la empresa Farina Máquinas S.A donde se estableció un convenio de producción por el cual Farina Máquinas se dedicaría a la fabricación de máquinas ravioleras y D’alessio a las máquinas combinadas.

De esta manera el mercado es atendido por las dos empresas en cada especialidad.

Productos :

- Prensas para fideos (Fusileras)

- Máquinas combinadas (Fusileras y relleno)

- Ralladoras y picadoras individuales

- Amasadoras auxiliares

- Amasadoras térmicas

- Matrices para prensas

- Accesorios

Dentro de la línea de prensas para fideos se encuentran las fusileras en sus diferentes versiones con su registro y patente industrial.

\footnotetext{
${ }^{3}$ Cignacco,Bruno Roque -Fundamentos de comercialización internacional para Pymes1ª Edición
} ,Macchi 2004 
A continuación se detallan los productos con sus correspondientes características técnicas :

\begin{tabular}{|l|l|}
\hline Producto & Fusilera ${ }^{\circledR} 2$ Prensa para Fideos \\
\hline Características técnicas & $\begin{array}{l}\text { Gabinete de acero inoxidable ,amasadora } \\
\text { incorporada }\end{array}$ \\
\hline Motor & $\begin{array}{l}\text { Principal 4 HP corriente } / \mathrm{AC} 220 / 380 \\
\text {,amasadora } 2 \mathrm{HP} \text { corriente } / \mathrm{AC} 220 / 380\end{array}$ \\
\hline Capacidad productiva & $60 / 90 \mathrm{Kg} / \mathrm{hora}$ \\
\hline Dimensiones y peso & $\begin{array}{l}\text { Largo } 0,65 \mathrm{~m} \text { ancho } 0,60 \mathrm{~m} \text { alto } 1,60 \mathrm{~m} \\
\text { Peso :500 Kg }\end{array}$ \\
\hline
\end{tabular}

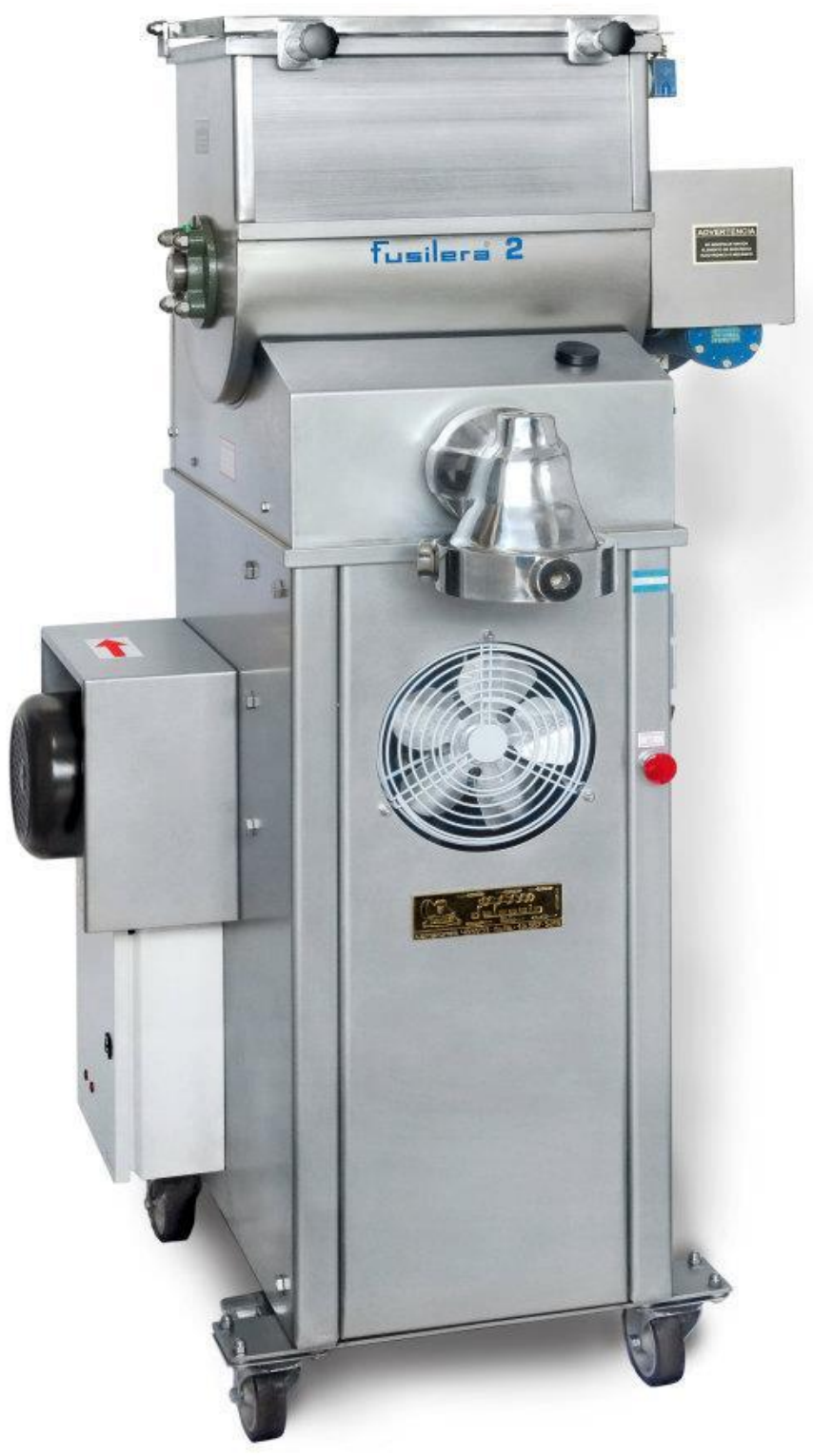

Imagen 1 Fusilera ${ }^{\circledR} 2$ Prensa para Fideos 


\begin{tabular}{|c|c|}
\hline Producto & Fusilera ${ }^{\circledR}$ Standard Prensa de Fideos \\
\hline Características técnicas & Gabinete de acero inoxidable o color \\
\hline Motor & Principal 2,5 HP corriente /AC 220/380 \\
\hline Capacidad productiva & $50 \mathrm{Kg} / \mathrm{hora}$ \\
\hline Dimensiones y peso & $\begin{array}{l}\text { Largo } 0,35 \mathrm{~m} \text { ancho } 0,80 \mathrm{~m} \text { alto } 1,40 \mathrm{~m} \\
\text { Peso : } 235 \mathrm{Kg}\end{array}$ \\
\hline
\end{tabular}

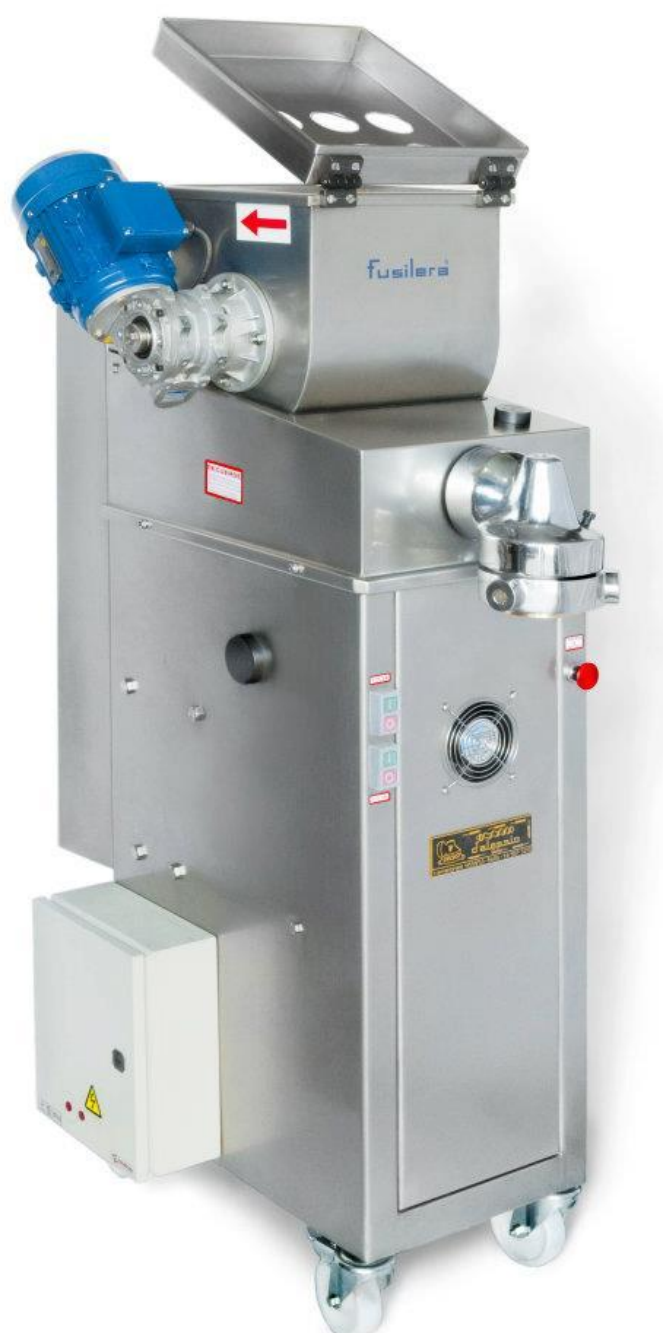

Imagen 2 Fusilera ${ }^{\circledR}$ Standard Prensa de Fideos 


\begin{tabular}{|l|l|}
\hline Producto & Nueva Fusilera® Super Lujo \\
\hline Características técnicas & $\begin{array}{l}\text { Gabinete de acero inoxidable ,rellena } \\
\text {,sella y corta automáticamente }\end{array}$ \\
\hline Motor & $\begin{array}{l}\text { Principal } 2,5 \mathrm{HP} \text { corriente } / \mathrm{AC} 220 / 380 \\
\text {,variador de velocidad para cortar distintos } \\
\text { largos de pastas rellenas }\end{array}$ \\
\hline Capacidad productiva & $50 / 60 \mathrm{Kg} / \mathrm{hora}$ \\
\hline Dimensiones y peso & $\begin{array}{l}\text { Largo } 0,95 \mathrm{~m} \text { ancho } 0,85 \text { alto } 1,45 \mathrm{~m} \\
\text { Peso }: 375 \mathrm{Kg}\end{array}$ \\
\hline
\end{tabular}

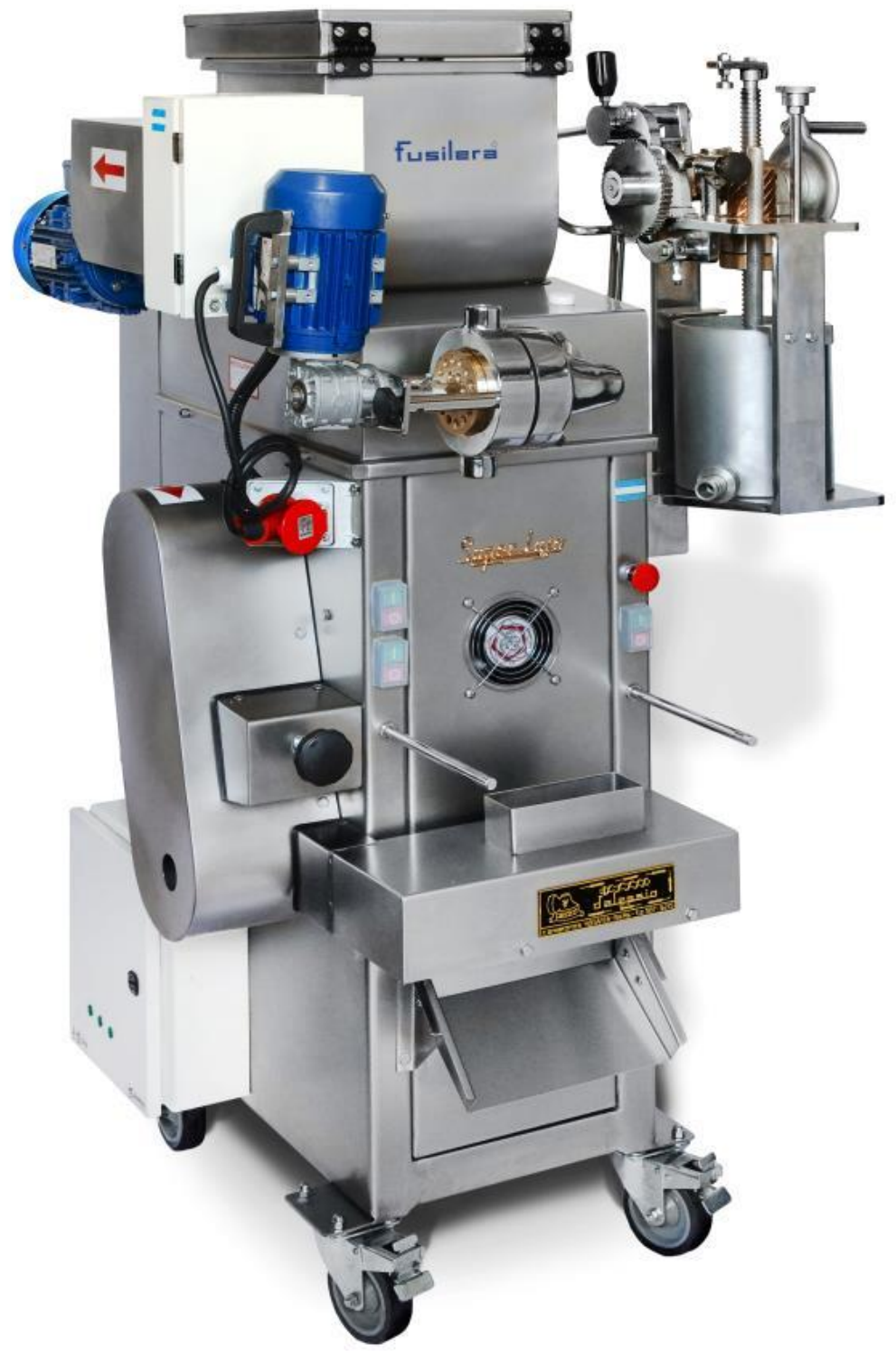

Imagen 3 Nueva Fusilera ${ }^{\circledR}$ Super Lujo 


\begin{tabular}{|l|l|}
\hline Producto & Máquina Combinada \\
\hline Características técnicas & $\begin{array}{l}\text { Gabinete de acero inoxidable, rodillo } \\
\text { rallador en acero inoxidable al cromo } \\
\text { niquel, para rallado grueso o fino del } \\
\text { queso. } \\
\text { Limpia, pica y ralla sustancias } \\
\text { alimenticias. }\end{array}$ \\
\hline Motor & 2 motores de $3 \mathrm{HP}$ corriente AC $220 / 380$ \\
\hline Capacidad productiva & $\begin{array}{l}\text { Rallado grueso } 200 \mathrm{Kg} / \mathrm{hora} \\
\text { Picadora } 700 \mathrm{Kg} / \mathrm{hora}\end{array}$ \\
\hline Dimensiones y peso & $\begin{array}{l}\text { Largo } 0,80 \mathrm{~m} \text { ancho } 0,50 \mathrm{~m} \text { alto } 1,75 \mathrm{~m} \\
\text { Peso :355 Kg }\end{array}$ \\
\hline
\end{tabular}

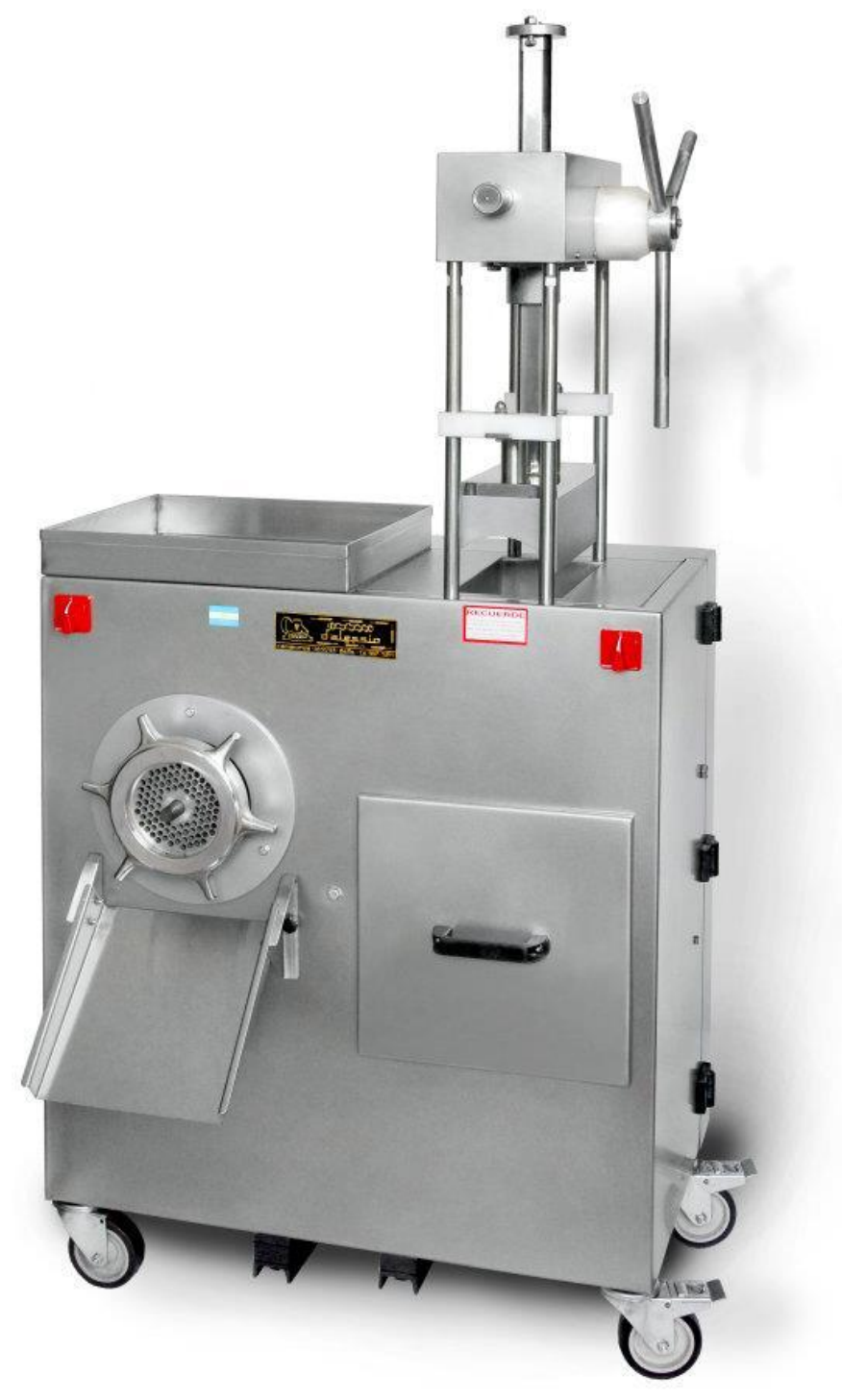

Imagen 4 Máquina Combinada 


\begin{tabular}{|l|l|}
\hline Producto & Ralladora o Picadora individual \\
\hline Características técnicas & $\begin{array}{l}\text { Gabinete de acero inoxidable ,rodillo } \\
\text { rallador en acero inoxidable al cromo } \\
\text { niquel,para rallado grueso o fino del } \\
\text { queso. }\end{array}$ \\
\hline Motor & 2 motores de $3 \mathrm{HP}$ corriente $\mathrm{AC} 220 / 380$ \\
\hline Capacidad productiva & Rallado grueso $70 \mathrm{Kg} / \mathrm{hora}$ \\
\hline Dimensiones y peso & $\begin{array}{l}\text { Largo } 0,40 \mathrm{~m} \text { ancho } 0,50 \mathrm{~m} \text { alto } 1,75 \mathrm{~m} \\
\text { Peso }: 355 \mathrm{Kg}\end{array}$ \\
\hline
\end{tabular}

Imagen 5 Ralladora o Picadora individual 


\begin{tabular}{|l|l|}
\hline Producto & Amasadora Auxiliar \\
\hline Características técnicas & $\begin{array}{l}\text { Totalmente de aluminio anticorrosivo y } \\
\text { acero inoxidable. } \\
\text { Batea enteriza en acero inoxidable } \\
\text { higiénica y sin pintura }\end{array}$ \\
\hline Motor & $\begin{array}{l}\text { Con mechero de 18.000 cal./hora para } \\
\text { gas natural, garrafa o supergas. } \\
\text { Motor: } 2 \mathrm{HP} \text { Corriente/ AC 220/ 380 / 3HP }\end{array}$ \\
\hline Capacidad productiva & 50 a $100 \mathrm{Kg} /$ hora \\
\hline Dimensiones y peso & $\begin{array}{l}\text { Largo } 0,70 \mathrm{~m} \text { ancho } 0,40 \mathrm{~m} \text { alto } 0,90 \mathrm{~m} \\
\text { Largo } 1,60 \mathrm{~m} \text { ancho } 0,60 \mathrm{~m} \text { alto } 1,00 \mathrm{~m} \\
\text { Peso }: 85 / 300 \mathrm{Kg}\end{array}$ \\
\hline
\end{tabular}

Imagen 6 Amasadora Auxiliar 


\begin{tabular}{|l|l|}
\hline Producto & Amasadora Térmica \\
\hline Características técnicas & $\begin{array}{l}\text { Totalmente de aluminio anticorrosivo y } \\
\text { acero inoxidable. } \\
\text { Batea enteriza en acero inoxidable } \\
\text { higiénica y sin pintura } \\
\text { La especialidad de esta máquina es el } \\
\text { cocinado de masa para ñoquis. También } \\
\text { amasa los rellenos generales y cualquier } \\
\text { otro uso como amasadora. } \\
\text { Fácil manejo y limpieza } \\
\text { Evita desperdicios }\end{array}$ \\
\hline Motor & $\begin{array}{l}\text { Con mechero de 18.000 cal./hora para } \\
\text { gas natural, garrafa o supergas. } \\
\text { Motor: } 1 \mathrm{HP} \text { Corriente/ AC 220/ 380 / }\end{array}$ \\
\hline Capacidad productiva & $\begin{array}{l}\text { Dos tamaños 20/40 Kg. Capacidad para } \\
\text { amasado de ñoquis hasta 40Kg. } \\
40 \text { a 80Kg./Hora Incluyendo el hervido del } \\
\text { agua. }\end{array}$ \\
\hline Dimensiones y peso & $\begin{array}{l}\text { Largo 0,65m ancho 0,60m alto 0,95 m } \\
\text { Largo 0,85m ancho 0,80m alto 1,20 m } \\
\text { Peso :135 /275 Kgs }\end{array}$ \\
\hline
\end{tabular}

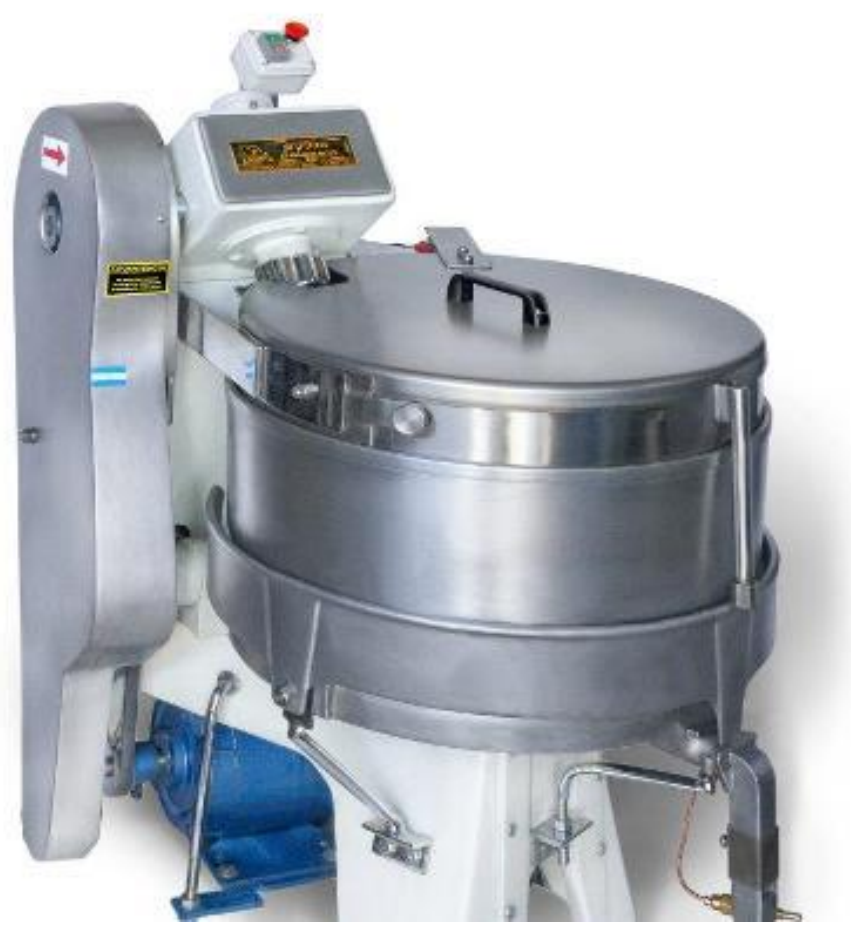

Imagen 7 Amasadora Térmica 


\section{PLAN DE NEGOCIOS}

El producto principal que se comercializará internacionalmente en una primera etapa bajo la marca D'alessio será la máquina Nueva Fusilera Super Lujo, con registro de patente industrial № 179799 y 179715 .

Posteriormente se complementará con otros productos de su portfolio.

\subsection{Características del producto}

Capacidad productiva de 50/60 Kg /hora .Su motor principal es de 2,5 HP /corriente AC 220/380, dispone de un variador de velocidad que permite cortar en distintos largos las pastas rellenas .Su gabinete exterior es de Acero Inoxidable calidad AISI 304 .Sus medidas son (Largo 0,95m x Ancho 0,85m x Altura 1,45m) y su peso neto es de $375 \mathrm{Kg}$. El diseño es innovador, ocupa poco espacio físico y tiene la característica de poder elaborar diferentes tipos de fideos y además fideos rellenos por lo que se la define como dos en uno brindando una ventaja competitiva a la hora de ser comparada con otras máquinas de la industria .La empresa proporcionará un servicio de post venta y una garantía de un año por posibles deficiencias que puedan sufrir los principales elementos de la misma que serán establecidos en el contrato de compra venta internacional .

3.2 Clasificación del producto en el N.C.M (nomenclador común del Mercosur).

De las reglas generales para la interpretación del sistema armonizado de clasificación de las mercaderías, se obtiene la clasificación de los productos en la sección XVI Máquinas y aparatos, material eléctrico y sus partes ; aparatos de grabación o de reproducción de imágenes y sonido en televisión ,y las partes y accesorios de estos aparatos.

La nota de sección Cap.84 Reactores nucleares, calderas ,máquinas, aparatos y artefactos mecánicos ;partes de estas máquinas o aparatos ${ }^{4}$.

Finalmente es el N.C.M 8438.10 .00

\footnotetext{
${ }^{4}$ Nomenclador Común del Mercosur http://www.aduanaargentina.com/nc.php extraído el día 9/02/2013 


\section{Descripción :}

De rellenar

Máquinas y aparatos para la fabricación de pastas alimenticias

- Máquinas y aparatos para panadería, pastelería, galletería o la fabricación de pastas alimenticias máquinas y aparatos, no expresados ni comprendidos en otra parte de este capítulo, para la preparación o fabricación industrial de alimentos o bebidas, excepto las máquinas y aparatos para extracción o preparación de aceites o grasas, animales o vegetales fijos.

Capítulo 84

Reactores nucleares, calderas, máquinas, aparatos y artefactos mecánicos; partes de estas máquinas o aparatos.

Partida 8410

Máquinas y aparatos, no expresados ni comprendidos en otra parte de este capítulo, para la preparación o fabricación industrial de alimentos o bebidas, excepto las máquinas y aparatos para extracción o preparación de aceites o grasas, animales o vegetales fijos.

Sub partida y Sub partida regional 8410.10 .00 - Máquinas y aparatos para panadería, pastelería, galletería o la fabricación de pastas alimenticias.

\subsubsection{U SIM (Sistema informático María) ítem De rellenar}

\section{2 .1 Reglamentación y Normas para la exportación}

Determinada la posición arancelaria del producto se analizarán los requisitos e intervenciones necesarias para realizar la exportación.

\subsubsection{Requisitos Aduaneros y aranceles de exportación}

-Contratación de un despachante de Aduana.

-Actualización e inscripción como importador /exportador en el Sistema Registral .

-El producto no requiere de intervenciones previas

-Para la exportación esta máquina percibe un reintegro del $6 \%$ sobre el precio 
FOB y tributa un arancel en concepto de derecho de exportación del $5 \%$.

3.2.3 Mercado Único y Libre de Cambios

Los exportadores deben ingresar al sistema financiero los fondos provenientes de las operaciones de exportación dentro de los $\mathbf{3 6 0}$ días corridos contados a partir de la fecha en que se haya efectivizado el embarque. ${ }^{5}$

\subsubsection{Embalaje para exportación:}

Se diseñara un embalaje adecuado para exportación que cubra los riesgos logísticos que implica el transporte internacional considerando todos los posibles medios de transporte (aéreo, terrestre y marítimo).

Cajón de madera fumigada cumpliendo normas internacionales, rotulado detallando nombre del fabricante, marca, modelo, y cliente del exterior indicando además que se trata de un PRODUCTO PARA EXPORTACIÓN de INDUSTRIA ARGENTINA.

Peso Neto: $375 \mathrm{Kg}$

Peso Bruto: $425 \mathrm{Kg}$

Medidas del cajón :(Largo $1 \mathrm{~m} \times$ Ancho 0,90 m x Altura 1,50 m) sobre pallet de iguales medidas con fijaciones y sujeciones que eviten su desplazamiento.

El comprador habitualmente especifica las marcas de exportación necesarias para facilitar la recepción en destino.

A partir de estos pesos y medidas podremos determinar el costo del flete internacional a ser utilizado.

\subsubsection{Plan Financiero}

Para llevar a cabo el plan de negocios la empresa invertirá en un centro de mecanizado con recursos propios que le permitirá producir dos máquinas en forma mensual de las cuales se proyectará la venta de una máquina cada dos

\footnotetext{
${ }^{5}$ Mercado Único de Divisas Res.MEFP 231/12 Res.MEFP 142/12 www.pcram.net extraído el día $13 / 2 / 2013$ 
meses a partir de los primeros seis meses de la fecha de inicio del proyecto .EI costo de la inversión inicial será de U\$S 50.000 .

\subsection{Fortalezas y Debilidades}

\subsubsection{Fortalezas}

Inversión inicial relativamente baja.

Producto innovador de alta producción.

Posibilidad de complementar el producto con otros de su portfolio.

Flexibilidad a la producción.

Capacidad de ampliar su producción.

Afianzar el producto en el mercado interno como alternativa o complemento a la exportación a futuro.

\subsubsection{Debilidades}

Inexperiencia en Negocios internacionales.

Poca intervención en Ferias y rondas de negocios.

Capacidad de producción acotada.

\subsubsection{Oportunidades}

Incremento del consumo de pastas a nivel mundial.

Bajas barreras de salida.

Máquina dos en uno permite elaborar pastas rellenas y fideos.

A nivel región mediante los acuerdos y tratados vigentes los niveles de aranceles son inferiores a los que se practican con países no integrantes.

Certificar productos con normas de calidad. 


\subsubsection{Amenazas}

Competencia en el mercado de máquinas italianas, muy bien posicionadas en la mente del consumidor a nivel nacional y mundial.

\section{IDENTIFICACION DE LOS MERCADOS POTENCIALES}

Como consecuencia del diagnóstico interno que presenta la empresa D’alessio , donde su experiencia en los negocios internacionales es escasa y a los efectos de obtener ventajas tanto logísticas como competitivas se han seleccionado tres países alternativos integrantes del Mercosur para ser analizados ,entre ellos: Brasil ,Chile y Uruguay .

Si bien a priori Brasil presenta características muy interesantes en términos de volumen poblacional e indicadores económicos, el consumo de 6,4 kilos por habitante, predominó en el 2010, la preferencia por las pastas secas (5,2 kilos por habitante), seguido de las pastas instantáneas (0,9 kilos per capita) y luego las pastas frescas, según cifras de ABIMA - Asociación Brasileña de Industrias de Masas Alimenticias. El mercado brasileño es un actor importante en la producción de pastas alimenticias a nivel mundial. Según la misma fuente de información, su volumen de producción anual asciende a más de un millón de toneladas, situándose como el tercer productor global, por debajo de Italia y Estados Unidos. A nivel mundial, el principal país consumidor de pastas es Italia, seguido de Venezuela y Túnez. Hay, además, una diferencia con respecto a la producción y el consumo: en Italia se consumen mayoritariamente pastas secas, mientras que en Sudamérica las ventas están más equilibradas entre frescas y secas. ${ }^{6}$

Chile es el segundo consumidor en Latinoamérica, ubicándose en la posición $\mathrm{N}^{\circ} 8$, con un consumo por habitante de 8,4 kilos según la International Pasta

Organisation. Durante el año 2010 se consumieron aproximadamente (119.200) toneladas de pastas de las cuales (118.400) toneladas de pastas secas y 800 toneladas de pastas frescas. ${ }^{7}$

\footnotetext{
${ }^{6}$ ABIMA -Asociación Brasileña de Industrias de Masas Alimenticias http://abima.com.br/estMercNacMassas.asp extraído el día 15 de Febrero de 2013 ${ }^{7}$ International Pasta Organisation http://www.internationalpasta.org extraído el día 15 de Febrero de 2013 
Tanto Brasil como Chile son grandes consumidores de pastas, pero las costumbres y los hábitos en el consumo se concentran en las pastas secas. En Uruguay, este rubro comprende varios segmentos: pastas frescas, pastas envasadas al vacío, pastas secas (fideos), masas de hojaldre y salsas. La venta anual de todo el sector, incluyendo fideerías, está en el entorno de las 25.000 toneladas, según un estudio realizado por Equipos Retail. Esto supone un consumo per cápita de unos 7,5 kilos por año, cifra similar a la de Argentina pero muy inferior a la de Italia, el país consumidor por excelencia con 28 kilos anuales. ${ }^{8}$

El consumo de pastas frescas y envasadas al vacío en Uruguay es de aproximadamente unas 13.000 toneladas por año, de acuerdo con estimaciones de la Cámara Uruguaya de Fabricantes de Pastas. La "pasta", vocablo de origen italiano que abarca todas las variedades de formas y tamaños de productos elaborados con harina y agua, es uno de los alimentos básicos de la dieta de los uruguayos por sus excelentes propiedades nutritivas y su precio muy accesible. ${ }^{9}$

Si consideramos las ventajas logísticas podemos decir que la vecindad geográfica representa un factor estratégico en la decisión de nuestro mercado de destino:

Costos menores en transportes.

Fácil acceso.

Disponibilidad inmediata de medios de transportes tanto: aéreos, lacustres y terrestres.

Lead time reducido.

Idioma.

Las ventajas económicas son claramente notorias frente a la competencia internacional, al aplicar el régimen de importación de Normas de Origen vigente en el Mercosur.

\footnotetext{
${ }^{8}$ http://www.equiposretail.com.uy extraído el día 15 de Febrero de 2013

9 http://www.pasterosuruguayos.com extraído el día 15 de Febrero de 2013 
Para los países signatarios, mediante la certificación de origen del producto la tributación arancelaria es del $0 \% .{ }^{10} \mathrm{El}$ arancel extrazona para los países no signatarios es del $14 \%$ y los precios de los productos similares oscilan entre los 25000 y 30000 Euros. $^{11}$

Por lo expuesto anteriormente Uruguay se presenta como la elección más atractiva para el desarrollo de nuestro plan de negocios de exportación.

\subsection{URUGUAY}

\subsubsection{Aspectos generales}

Uruguay está ubicado en América del Sur, sobre la costa atlántica entre Brasil al Noreste y Argentina al oeste. Tiene una superficie de 176.000 km2 y 138.000 km2 de aguas jurisdiccionales. Montevideo, su capital, es el centro administrativo del MERCOSUR. Las ciudades más populosas son Montevideo, así como Paysandú y Salto, sobre la costa del Río Uruguay y Punta del Este, sobre la costa atlántica, a 120 kilómetros de Montevideo, uno de los balnearios más conocidos en América del Sur. La población del Uruguay es de 3.344.938 habitantes, de los cuales cerca de 1,5 Millones viven en Montevideo y sus alrededores. Para el conjunto del país Aproximadamente el $90 \%$ de la población es urbana. Su moneda es el peso uruguayo .No existe población indígena; un alto porcentaje de los uruguayos son Descendientes de inmigrantes europeos, principalmente españoles e italianos. El crecimiento de la población es uno de los más bajos de América Latina: 0,6\% Por año. ${ }^{12}$

\footnotetext{
${ }^{10}$ Aiera Asociación de importadores y Exportadores de la República Argentina www.aiera.org

${ }^{11}$ Dominioni Punto \& Pasta www.dominioni.it extraído el día 10 de Enero de 2013

${ }^{12}$ http://www.argentinatradenet.gov.ar/sitio/mercado/material/GUIA NEGOCIOS 2012 


\subsubsection{Economía y Negocios}

Si bien el sector servicios absorbe la mayor parte del PBI, la principal fuente De riqueza del país (y fuente de divisas) es la agroindustria, que supone más del $60 \%$ de las exportaciones totales. En cualquier caso, la matriz productiva del Uruguay está sufriendo importantes transformaciones, especialmente por la Importancia del sector forestal, que ha comenzado a transitar la fase de Industrialización de la madera en forma generalizada, en base al stock disponible Obtenido de los bosques sembrados en los últimos quince años. Uruguay es un país agro exportador, por lo que la agricultura (arroz, trigo, maíz, girasol, lino, soja, remolacha azucarera, caña de azúcar) y la ganadería (vacunos, ovinos) son los recursos fundamentales de su economía. Las industrias principales son la lechera y sus derivados, papel, cartón, fertilizantes, alcoholes, cemento y refinación de hidrocarburos. Si bien los recursos minerales y energéticos son escasos, existen grandes yacimientos de ágatas en el norte del país, como de granito, mármol, y extracción de oro en la localidad de Minas de Corrales.

En el sector servicios, los principales sectores son el turismo, el sector financiero, los servicios logísticos y de transporte. Otro de los principales ingresos económicos del país es el turismo que cuenta con una línea costera sobre el Río de la Plata y el Océano Atlántico está salpicado de balnearios, entre los que se destacan Punta del Este y Piriápolis, de fama internacional. El turismo agropecuario, histórico y termal también tiene importancia. Algunas de las grandes empresas multinacionales como BOTNIA y WEYERHAEUSER ya se han instalando en Uruguay. Otras como Stora-Enso o Portucel tienen importantes proyectos en estudio, permitiendo que la industria de transformación de la madera (química y mecánica) pase a cobrar un papel determinante. Entre las principales vulnerabilidades de la estructura económica del país cabe destacar su dependencia energética, puesto que prácticamente la única fuente de energía primaria existente es la hidroeléctrica. Una de las grandes apuestas futuras del país en este ámbito está en las energías renovables, especialmente la energía 
eólica. Uruguay es miembro del MERCOSUR y sus principales socios comerciales son la Argentina, Brasil y China. ${ }^{13}$

4.1.3 Principales indicadores económicos del Uruguay

Cuadro 2 :Principales Proyecciones económicas

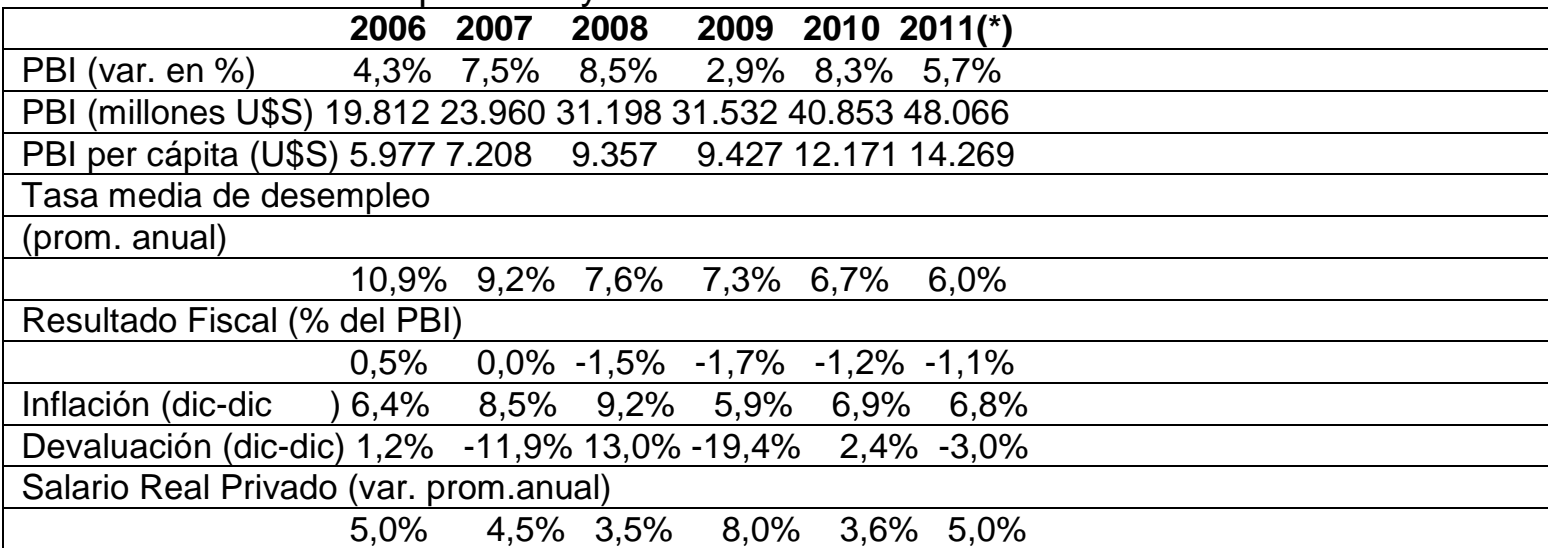

Fuente: Subsecretaría de Comercio Internacional .Dirección General de Estrategias de Comercio

Exterior de la República Argentina

Cuadro 3 :Sector Externo

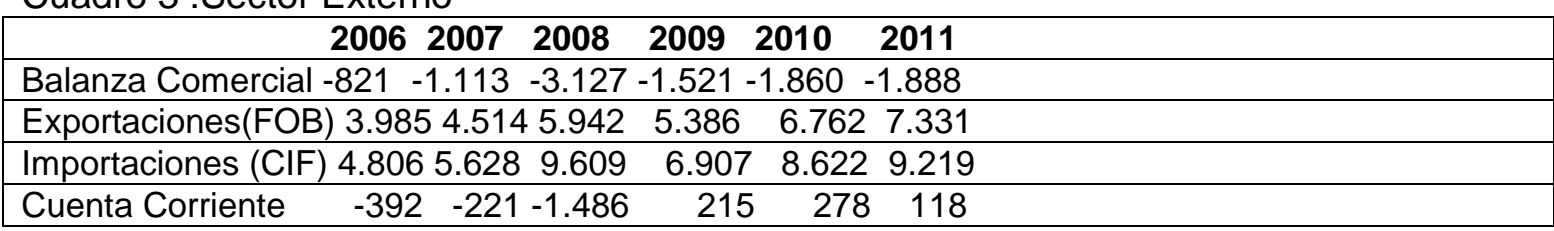

Fuente: Subsecretaría de Comercio Internacional .Dirección General de Estrategias de Comercio Exterior de la República Argentina

\subsubsection{Balanza comercial Uruguay -Argentina}

Las relaciones comerciales entre Uruguay y Argentina han sido de gran relevancia para el sector externo uruguayo, dado que Argentina es uno de los principales socios tanto en las exportaciones como en las importaciones.

El saldo de la balanza comercial entre Uruguay y Argentina fue deficitario para todo el periodo comprendido entre 2001-2011. No obstante, en los últimos tres años, el déficit se ha profundizado fundamentalmente por el fuerte aumento de las importaciones, llegando al año 2011 con el mayor saldo negativo (US\$1.238 millones).

\footnotetext{
${ }^{13}$ Subsecretaría de Comercio Internacional. Dirección General de Estrategias de Comercio Exterior de la República Argentina- Infocopa Uruguay 2011-Información comercial por país.
} 
Al analizar la evolución de las exportaciones uruguayas de bienes a dicho destino se constata que estas presentan una tendencia creciente, registrando un crecimiento interanual promedio del $6,6 \%$ en el periodo $2001-2011$.

Luego de la crisis de 2002, las exportaciones hacia Argentina presentaron un crecimiento sostenido hasta el año 2008 inclusive, para descender durante el 2009 en más de 30\%.

Gráfico № 1- Exportaciones uruguayas de Bienes hacia Argentina (Millones U\$S)

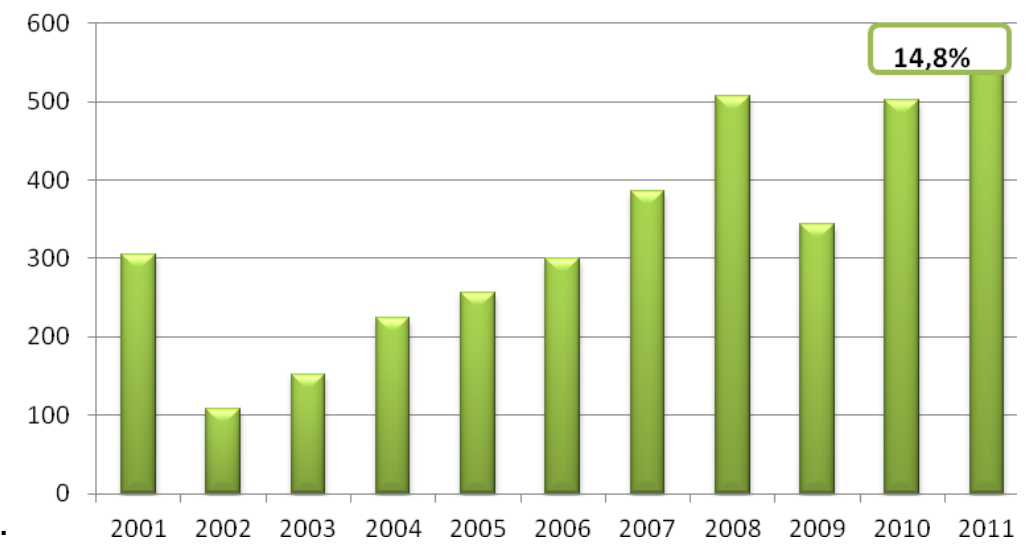

Fuente: Subsecretaría de Comercio Internacional .Dirección General de Estrategias de Comercio Exterior de la República Argentina.

En 2010 las ventas al exterior totalizaron US\$ 502 millones, lo que implicó un aumento significativo del orden del $46 \%$ con respecto al año 2009 , lo que permitió alcanzar niveles similares a los del año 2008. Por su parte en 2011, las ventas hacia Argentina llegaron a un nuevo récord de US\$576, lo que significa un aumento de $14 \%$ respecto a 2010.

Por su parte, las importaciones tuvieron un comportamiento en tendencia similar al de las exportaciones en los últimos años.

Esto implica que las compras desde Argentina se han casi duplicado (desde el año 2005), al igual que las ventas, lo que explica que el déficit comercial también se haya casi duplicado en el mismo periodo. En el 2011 las importaciones desde Argentina aumentaron casi en $30 \%$ en relación al año $2010 .{ }^{14}$

\footnotetext{
${ }^{14}$ URUGUAY XXI - Instituto de Promoción de Inversiones y Exportaciones http://www.uruguayxxi.gub.uy 
Gráfico 2: Importaciones uruguayas de Bienes desde Argentina (Millones U\$S)

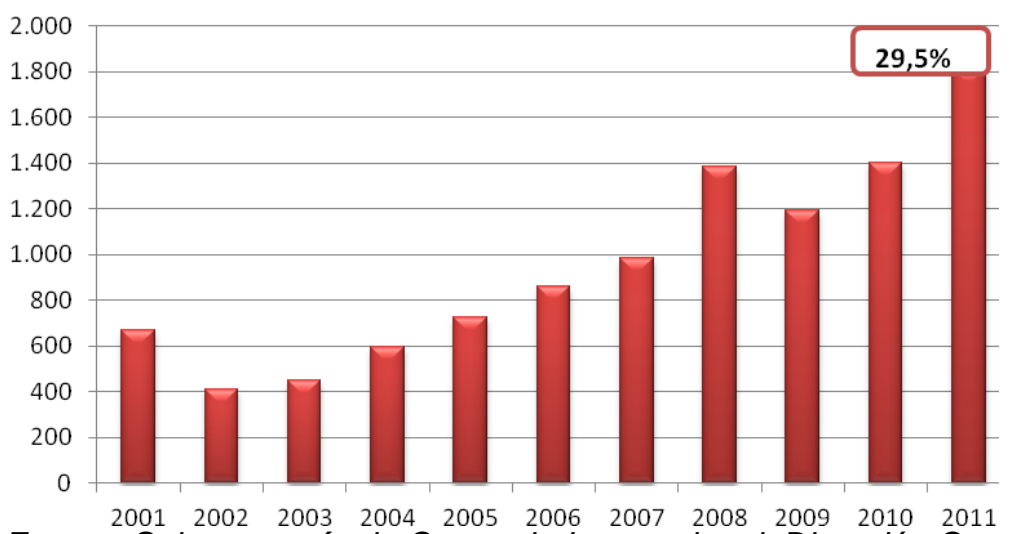

Fuente: Subsecretaría de Comercio Internacional .Dirección General de Estrategias de Comercio Exterior de la República Argentina.

Cuadro 4: Intercambio comercial entre Uruguay y Argentina (Millones U\$S)

\begin{tabular}{|c|c|c|c|c|}
\hline Periodo & Expo Arg & Impo Arg & Saldo & Com Bil \\
\hline 2003 & 531,3 & 163,50 & 367,80 & 694,80 \\
2004 & 662,96 & 226,60 & 436,36 & 889,56 \\
2005 & 844,62 & 268,76 & 575,86 & 1113,38 \\
2006 & 1174,82 & 301,19 & 873,63 & 1476,01 \\
2007 & 1173,37 & 458,43 & 714,94 & 1631,8 \\
2008 & 1174,42 & 527,16 & 1237,26 & 2291,58 \\
2009 & 1606,29 & 348,26 & 1258,03 & 1954,55 \\
2010 & 1552,15 & 586,74 & 956,41 & 2138,89 \\
\hline
\end{tabular}

Fuente: Fundación Exportar en base de datos infojust

El siguiente cuadro nos demuestra el crecimiento del comercio bilateral entre los dos países durante los últimos años desde el año 2003 al 2010 .Podemos decir que prácticamente aumentó en un $300 \%$.

\subsubsection{Infraestructura, transporte y comunicaciones}

La ubicación estratégica de Uruguay en el centro del MERCOSUR, lo convierte en el enlace natural para las comunicaciones entre los países miembros.

El puerto de Nueva Palmira, situado en el extremo sur de la Hidrovía Paraguay-Paraná, es un punto estratégico para el ingreso y egreso de mercaderías hacia el centro del continente. Los servicios de telecomunicaciones, energía y agua se encuentran disponibles sin restricciones en todo el país, con muy buenos niveles tecnológicos. Por su ubicación geográfica Uruguay es un 
enlace permanente de comunicaciones terrestres y marítimas entre los países del MERCOSUR, especialmente Argentina y Brasil. Su sistema de transporte cuenta con infraestructuras existentes y en pleno desarrollo que lo habilita para atender la demanda de transporte de los fuertes flujos de intercambios entre los países miembros del MERCOSUR y de los requerimientos particulares de los países de la región para sus intercambios internacionales. ${ }^{15}$

\subsubsection{Transporte carretero}

La red vial nacional cuenta con $8.696 \mathrm{~km}$. de carreteras de dos o más carriles según el Ministerio de Transportes y Obras Públicas, que se distribuyen en los $176.000 \mathrm{~km}^{2}$ de territorio. La mayoría de las carreteras confluyen en la capital, Montevideo. Las principales rutas y carreteras del país tienen en general buen mantenimiento y señalización. El transporte internacional de carga se efectúa sin restricciones a través de diversos pasos de frontera entre Uruguay, Argentina, Brasil, Chile y Paraguay, con una flota disponible sin limitaciones. El transporte interno de pasajeros se realiza mayoritariamente por ómnibus a cargo de empresas privadas bajo un régimen de "competencia regulada", que ha permitido una solución con altos estándares de calidad y eficiencia. Las interconexiones con los países vecinos se llevan adelante a través de diversos pasos de frontera: con Argentina existen tres puentes sobre el Río Uruguay en las ciudades de Salto, Paysandú y Fray Bentos, mientras que con Brasil las carreteras se unen en las ciudades de Artigas, Rivera, Río Branco y Chuy. ${ }^{16}$

\subsubsection{Transporte ferroviario}

La red ferroviaria del Uruguay es de trocha estándar, de vía simple, excepto 11 $\mathrm{Km}$. de doble vía en el acceso a Montevideo. El sistema es operado por la Administración de Ferrocarriles del Estado (AFE), una empresa estatal autónoma, que actualmente está abierta a la participación de operadores privados para el transporte de carga. La red está estructurada en tres líneas troncales que

\footnotetext{
${ }^{15} \mathrm{http} / / /$ www.argentinatradenet.gov.ar/sitio/mercado/material/GUIA NEGOCIOS 2012.pdf

${ }_{16}$ http://www.argentinatradenet.gov.ar/sitio/mercado/material/GUIA NEGOCIOS 2012.pdf
} 
confluyen en la nueva Estación, contigua al Puerto de Montevideo.Los servicios de transporte ferroviario de pasajeros son brindados en dos pequeños segmentos interurbanos de corta distancia, de escasa importancia para el sistema. ${ }^{17}$

\subsubsection{Transporte fluvial y marítimo}

El Puerto de Montevideo, principal puerto nacional, recibe líneas navieras de todo el mundo y concentra el comercio de exportación, importación o tránsito. Es la primera y única terminal de la costa atlántica de Sudamérica que opera bajo un régimen de Puerto Libre. El recinto portuario es zona de exclusión aduanera donde, a través de operadores privados, es posible acceder a diversos servicios de nivel internacional: terminal de contenedores, almacenamiento, y otros. Este régimen se aplica también a los puertos comerciales de Fray Bentos, Nueva Palmira, Colonia, Sauce y La Paloma. ${ }^{18}$

\subsubsection{Transporte aéreo}

Las principales instalaciones aeroportuarias están ubicadas en zonas cercanas a la mayor concentración de población e infraestructura turística (Montevideo y Punta del Este).El nuevo Aeropuerto Internacional de Carrasco Puerta del Sur S.A., inaugurado en diciembre de 2009 con un diseño arquitectónico de alta innovación tecnológica, está ubicado en el departamento de Canelones, Ruta 101, km. 19.950.La nueva terminal se desarrolla en dos niveles principales, con vialidades diferenciadas y dedicadas para los flujos de arribos y partidas, respectivamente. El edificio ocupa una superficie de más de $45.000 \mathrm{~m} 2$, y está dotado de 8 puertas de embarque, cuatro de ellas equipadas con mangas telescópicas. Maneja una capacidad de 4 millones y medio de usuarios al año. El Aeropuerto Internacional de Punta del Este (Laguna del Sauce) cuenta con una pista de 2.133 metros de largo y 45 de ancho capaz de operar grandes aeronaves. La terminal es un gran edificio en dos niveles subsuelo.

Técnicamente puede operar hasta cinco Boeing 737 en su plataforma comercial, y destina una superficie de 50.000 metros cuadrados para operaciones de

\footnotetext{
${ }^{17} \mathrm{http}: / /$ www.argentinatradenet.gov.ar/sitio/mercado/material/GUIA_NEGOCIOS_2012.pdf

${ }^{18} \mathrm{http}: / /$ www.argentinatradenet.gov.ar/sitio/mercado/material/GUIA_NEGOCIOS_2012.pdf 
aeronaves particulares. ${ }^{19}$

4.1.10 Normas legales para el ingreso de productos en Uruguay

- El importador deberá tener una empresa (unipersonal, S.A., S.R.L., etc.) registrada e inscripta ante la Dirección General Impositiva (DGI), el Banco de Previsión Social (BPS) y el Banco de Seguros del Estado (BSE).

- El importador solicita los servicios de un Despachante de Aduana (Asociación de Despachantes de Aduana del Uruguay)

- El Despachante de Aduana, de acuerdo a los documentos remitidos por el importador y previa clasificación de la mercadería en la Nomenclatura Común del Mercosur (NCM), confecciona y envía el Documento Único Aduanero (DUA) junto con la liquidación tributaria por el monto correspondiente a la Dirección Nacional de Aduanas (DNA).

- La DNA (de no haber diferencias en la liquidación o errores) remite al despachante la liquidación correspondiente a la importación.

- Una vez efectuado el control del DUA por parte de la DNA y aceptada la liquidación por parte del despachante, el DUA es validado y numerado por la DNA. Paralelamente la DNA informa al Banco de la República Oriental del Uruguay (BROU) respecto las cantidades correspondientes por cada tributo a cobrar y el número de DUA otorgado.

- Una vez que el despachante recibe el número de registro del DUA, efectúa el pago de la liquidación en el BROU, el que a su vez, comunica a la DNA el cobro correspondiente.

- El despachante recibe por la DNA el monto a pagar por los tributos y el decreto del canal de comprobación asignado:

- Rojo: verificación de la mercadería y de los documentos.

Naranja: Verificación de los documentos.

Verde: No hay verificación. (Se verifica únicamente a posteriori o por un verificador, si entiende que corresponde).

- Se imprime el DUA en la Aduana, se da entrada de la mercadería y se lo ensobra junto con una declaración jurada, la cual debe ser firmada por el

${ }^{19} \mathrm{http} / /$ www.argentinatradenet.gov.ar/sitio/mercado/material/GUIA NEGOCIOS 2012.pdf 
despachante y el importador - así como con la Factura Comercial, el Conocimiento de Embarque, el Certificado de Origen, el Packing List (Documento cuyo fin es la descripción de la mercadería) y con toda aquella documentación requerida de acuerdo al producto que se trate.

- Se procede al desaduanamiento de la mercadería, abonando previamente los proventos portuarios (costos inherentes al trámite) en al ANP o en el Aeropuerto, según el caso.

- Se otorga el Cumplido Aduanero del DUA una vez examinada la mercadería por el verificador aduanero asignado. ${ }^{20}$

\subsubsection{Costo de introducción de las mercaderías importadas}

Las mercancías, para su introducción en el país, deben enfrentar diversos gastos: Arancel o Impuesto Aduanero Único (IMADUNI), cuando corresponda tasa consular. Los Impuestos Internos (IVA, adelanto IVA, IMESI), tasas de servicios, que cobra la Dirección Nacional de Aduanas, los proventos y otros costos portuarios los correspondientes a servicios fitosanitarios y análisis diversos, cuando corresponda la comisión del Despachante de Aduana.Se debe incluir además los gastos terminales (aéreo, marítimo, carga terrestre), previos a la importación de la mercadería, que depende del medio de transporte y de la forma de compra que se haya concertado (CIF, FOB) ${ }^{21}$

\subsubsection{Valoración aduanera}

La base imponible para la determinación de los derechos a la importación será el valor en aduana de las mercaderías importadas CIF de Importación . El valor en aduana de las mercaderías importadas será la base para la aplicación del Arancel Externo Común o de cualquier otro gravamen no arancelario establecido por disposiciones comunitarias específicas relativas a la importación de mercaderías. ${ }^{22}$

${ }^{20}$ Cámara Nacional de Comercio y Servicios del Uruguay www.cncs.com.uy www.anp.com.uy/institucional/marcolegal/default.asp

21 http://www.argentinatradenet.gov.ar/sitio/mercado/material/GUIA NEGOCIOS 2012.pdf $22 \mathrm{http}: / / \mathrm{www}$. argentinatradenet.gov.ar/sitio/mercado/material/GUIA NEGOCIOS 2012.pdf 


\subsubsection{Impuestos internos}

La Tasa Consular fue reimplantada por Ley № 17.296 (art. 585) del 21 de febrero del 2001 y tiene un nivel del $2 \%$ del valor CIF de los bienes importados. ${ }^{23}$ Tanto las importaciones como los artículos de producción nacional están gravados por dos impuestos indirectos: el Impuesto al Valor Agregado (IVA) y el Impuesto Específico Interno (IMESI). EI IVA, en el caso de las importaciones, se calcula sobre la suma del valor CIF, el arancel (si existe) y otros recargos. Se aplican dos tasas: una tasa mínima del 10\% y una tasa básica del $22 \%$, además un adicional del $10 \%$ como adelanto de ganancias. ${ }^{24}$

\subsubsection{Tasas de servicios}

Existen dos tasas de servicios percibidas por la Dirección Nacional de Aduanas. La Dirección Nacional de Aduanas percibe una tasa por servicios extraordinarios cuando el valor CIF de las importaciones es superior a 500 dólares. Esta tasa se aplica a cada uno de los permisos de importación que se tramiten. La tasa consiste en cantidades especificas (12, 30, 48, 108, 240 y 600 dólares) establecidas para seis tramos diferentes del valor de las importaciones. El equivalente de la tasa calculado como porcentaje del valor de las importaciones no supera el $2.5 \%$. Sin embargo, es probable que su incidencia sea mayor en el caso de las importaciones de poco valor que en el de las de valor elevado. ${ }^{25}$

Seguidamente se detallan las tasas actuales que se cobran por concepto de "servicios extraordinarios":

\footnotetext{
${ }^{23}$ http://www.parlamento.gub.uy/leyes/AccesoTextoLey.asp?Ley=17296\&Anchor=extraído el 23 de Febrero de 2013 http://www.anp.com.uy/institucional/marcolegal/default.asp http://www.uruguayxxi.gub.uy/innovaportal/v/368/1/innova.front/otros regimenes de promocion ${ }^{24} \mathrm{http} / / /$ www.argentinatradenet.gov.ar/sitio/mercado/material/GUIA NEGOCIOS 2012.pdf $25 \mathrm{http}: / /$ www.argentinatradenet.gov.ar/sitio/mercado/material/GUIA NEGOCIOS 2012.pdf 
Cuadro 5 :Tasa por servicios extraordinarios Valor CIF Tarifa

\begin{tabular}{|l|}
\hline de U\$S 500 hasta U\$S 1.000 U\$S 12 \\
\hline de U\$S 1.001 hasta U\$S $2.000 \cup \$ S 30$ \\
\hline de U\$S 2.001 hasta U\$S 8.000 U\$S 48 \\
\hline de U\$S 8.001 hasta U\$S 30.000 US 108 \\
\hline de U\$S 30.001 hasta U\$S 100.000 U\$ 240 \\
\hline de U\$S 100.001 en adelante U\$S 600 \\
\hline
\end{tabular}

Además, la Dirección Nacional de Aduanas percibe la tasa por servicios aduaneros que es el $0.2 \%$ del valor CIF de la importación hasta un máximo de 50 dólares.

\subsubsection{Costos portuarios}

La Administración Nacional de Puertos (ANP) percibe tributos portuarios como una contraprestación por servicios prestados a las mercaderías de importación en los recintos portuarios que administra. El tributo se aplica a las mercaderías arribadas a puerto por vía marítima o fluvial y descargadas con destino diferente al de transbordo o tránsito. Se liquida por tonelada métrica, según modalidad de la carga y de acuerdo al valor total por tonelada de la mercadería.Existen normas particulares de aplicación, con una tarifa binómica que se integran con un primer componente por tonelada, según modalidad de la carga y un segundo componente acorde al valor tonelada de la mercadería. El primer nivel tarifado de cada tipo de carga, corresponde al valor del primer componente de la tarifa. Es un 0,25\% sobre el valor CIF declarado. Los restantes niveles llevan agregado el segundo componente, que tiene carácter progresivo. Para la identificación del nivel aplicable a cada mercadería, se tomará el valor total por tonelada métrica, que figura en la correspondiente declaración, permiso o despacho aduanero. La tarifa se abonará previamente a la salida de la carga, del recinto portuario. La agencia marítima. Su tarifa se ubica entre 70 - 100 dólares por contenedor. En el caso del Aeropuerto Internacional de Carrasco, las importaciones tienen los costos de: Servicio de descarga, que cobran las compañías de aviación (entre U\$S 75 - 80 cada conocimiento de embarque).Costos de almacenaje. La 
compañía privada que gestiona los depósitos tiene una escala de tarifas de acuerdo al valor y el volumen de la mercadería. ${ }^{26}$

Cargo Fijo:

1 a 5 días U\$S 5,28 por embarque

6 a 120 días U\$S 8,22 por embarque

Almacenaje: 1 a $300 \mathrm{~kg} \ldots . . . \cup \$ S$ 0,011 x kg. x día Más de $300 \mathrm{~kg} \ldots$ U.. US 0,017 x kg. x día

$0,17 \%$ s/valor del permiso (por c/ 5 días de almacenaje)

\subsection{Mercado Meta}

El mercado uruguayo de pastas está compuesto por 130 fabricas de pastas en Montevideo y 150 en el interior ${ }^{27}$.Su volumen de ventas totaliza unas 13000 toneladas por año.

La falta de potestades del servicio bromatológico de la IMM está facilitando la operativa de numerosas empresas informales.$^{28}$

\subsubsection{Características del mercado de pastas}

Las pastas frescas tienen la particularidad de que deben ser elaboradas, vendidas y consumidas en el día o, como plazo máximo, a las 48 horas. Este mercado de las pastas está muy atomizado en Uruguay. Existen innumerables puestos de venta que no cumplen con los controles bromatológicos requeridos, venden mercadería elaborada con materias primas reprocesadas y con fechas de vencimiento muy superiores a las permitidas. La evolución tecnológica en esta área no es muy acentuada, se basa mayoritariamente en un proceso artesanal. El expendio directo, o sea en el mostrador, constituye uno de los principales canales de comercialización para las pastas frescas, aunque también se venden a través de almacenes y restaurantes. Las pastas envasadas al vacío tienen la característica de que son procesadas con una tecnología que les hace conservar sus propiedades por un período superior a un mes. Al tener una vida útil más

\footnotetext{
${ }^{26} \mathrm{http}: / /$ www.argentinatradenet.gov.ar/sitio/mercado/material/GUIA NEGOCIOS 2012.pdf 27 www.infouruguay.com.uy extraído el 20 de Febrero de 2013

28 www.montevideo.gob.uy Intendencia de Montevideo (Regulación alimentaria) extraído el 20 de Febrero de 2013
} 
prologada que las pastas frescas pueden ser distribuidas en forma masiva. Sin embargo, esta actividad impone mayores barreras para la entrada de nuevos actores en comparación con el negocio de las pastas frescas ya que la tecnología necesaria para elaborar este tipo de productos tiene un costo elevado y, por consiguiente, existe una mayor concentración de empresas. En el segundo trimestre de 2004 , se vendieron 20.027 kilos de pastas envasadas. La Especialista logró una participación del 35\% (7.010 kilos) del mercado, seguida por 5 Estrellas (ex La Sibarita) con un market share del 33\% (6.609 kilos), Cremona con el 10,6\% (2.133 kilos) y Marcello con el 2\% (390 kilos). A su vez, las marcas blancas de las cadenas abastecieron al 19,4\% (3.885 kilos) del total de la demanda. Según Carbajales de La Especialista, "el monto de inversión necesaria para instalar una planta de pastas envasadas, que requiere de un atmósfera modificada, depende del volumen de kilos a procesar y del tipo de envases a utilizar: rígidos o bolsas". Explicó que "las mejores máquinas son las italianas que implican un desembolso de U\$S 500.000 sin contar el costo del acondicionamiento del edificio. Adicionalmente, se precisa una envasadora alemana que tiene un costo de U\$S 75.000. Con estos equipos se procesan 400 kilos de pastas por hora aproximadamente. Estas cifras implican realizar una minuciosa preparación y evaluación del proyecto". La Especialista, a través de su red de distribuidores, abastece de pastas envasadas a todos los departamentos del Interior, los supermercados Disco, Devoto, Tienda Inglesa, Multiahorro y Tata, así como también fabrica las pastas al vacío de la marca Leader Price (perteneciente a Disco y Devoto) y Buon Mangiare (Multiahorro).Otra de las formas de comercialización de las pastas frescas es a través de los supermercados. Los Dos Leones, empresa fundada en 1926, abastece a las tres mayores cadenas: Disco, Devoto y Tienda Inglesa porque "ya conocemos la metodología de trabajo y tenemos un buen relacionamiento comercial que no se ha visto empañado por la absorción de algunos de estos negocios por diversos grupos económicos", afirmó el gerente Angel Soto de los Dos Leones. Otra de las empresas líderes del sector, La Especialista, también comercializa sus pastas frescas en las grandes superficies, incluyendo a Disco, Devoto, Multiahorro y Tienda Inglesa. Asimismo, elabora las denominadas "marcas blancas" de los supermercados Devoto y Tienda Inglesa con los mismos estándares de calidad 
que están presentes en su propia marca. COMPETENCIA. La literatura económica sostiene que las empresas participantes en un mercado deben buscar una ventaja competitiva con el objetivo de consolidar y/o ampliar su participación en el mismo. Dentro de las diversas fuentes de ventaja competitiva, se incluyen: proporcionar un servicio superior, obtener menores costos que los competidores, elaborar el producto con los estándares de calidad más elevados, etc. De esta forma, se brinda al consumidor un "valor superior" que hace que prefiera el producto elaborado por una empresa y no por otra, es decir que el consumidor logra diferenciar y crear una preferencia por un bien específico producido por determinada firma. En el mercado formal de las pastas de Uruguay, la competencia se da en la mayoría de los casos por la diferenciación del producto. Aquí cabe destacar el ingenio y la estrategia de las empresas para competir lealmente. La diferenciación se busca ya sea mediante la elaboración artesanal, desarrollando nuevas variedades y/o aplicando elevados estándares de calidad. "Hoy se observa un crecimiento de la demanda como consecuencia del continuo esfuerzo por parte de los negocios del sector por innovar y ofrecer variedades de sabores, formas y colores". El consumidor ha experimentado un cambio ya que, cuando va a la fábrica de pastas, busca variedad y productos diferentes. La pasta tradicional —como, por ejemplo, los tallarines_ ya no es la que más se vende sino que las pastas rellenas son las que tienen mayor salida, representando un $70 \%$ de las ventas. Dentro de esta categoría, la mitad del consumo corresponde a los ravioles. La competencia por precio se da en buena parte con otros renglones de la alimentación. "Si el precio de la carne aumenta, entonces el sustituto más cercano es la pasta, que constituye un excelente alimento a un costo accesible. Esa es una de las razones del incremento del consumo de pasta en los últimos tiempos", destaca Carbajales. Informalismo. Sin embargo, el surgimiento de una gran cantidad de empresas informales que compiten exclusivamente por precio, está dejando fuera de competencia a las pastas ofrecidas en los establecimientos comerciales habilitados y que cumplen con las disposiciones bromatológicas vigentes. Exportaciones. En Uruguay hubo algunas experiencias de ventas al exterior que no prosperaron. Entre 1996 y 1998 La Especialista tuvo una pequeña corriente exportadora de pastas envasadas a Río Grande del Sur (Brasil), que se interrumpió en 1999 por falta de competitividad debido a la devaluación del real. A 
su vez, Los Dos Leones exportó pastas congeladas, especialmente ravioles, al mercado norteamericano por un lapso mayor a un año en el período 2000-2001, aunque el monto total de los embarques no alcanzó a los U\$S 100.000. Para el presidente de la Cámara Uruguaya de Fabricantes de pastas, Carlos Pérez Sena, "la producción de pastas frescas en Uruguay está volcada al consumo interno. Es un mercado puntual, pero está bien atendido por las empresas. Si bien hubo algunos intentos de exportación, estos no resultaron". Las razones aducidas son que, por un lado, nuestro país no es competitivo en precio - aunque sí lo es en calidad- mientras que, por otro, existen diversas restricciones para-arancelarias en los países importadores. Agregó que "para exportar es necesario tener consolidado el mercado interno. El problema es que en Uruguay las pastas congeladas no tienen demanda interna porque la gente prefiere comprar directamente la pasta fresca en el comercio del barrio". IMPORTACIONES. Hubo consenso entre los empresarios uruguayos consultados que la importación de pasta al vacío o congelada no afecta mayormente a la venta de sus productos. En primer lugar, consideran que los consumidores saben elegir y diferenciar con respecto al sabor de los productos locales. En segundo lugar, existe el factor "poder adquisitivo" ya que medio kilo de pastas importadas cuesta $\$ 75$, mientras que un producto uruguayo similar se vende en una fábrica de pastas a \$ 54 en promedio. Para superar la contracción de las ventas durante la crisis económica, siete fábricas de pastas crearon el grupo Vera Pasta para trabajar en conjunto y poder hacer frente con mayor fuerza a la competencia de las pastas envasadas y de las elaboradoras informales. Los integrantes de este proyecto, que cuenta con el apoyo de la red Propymes y la agencia de cooperación alemana GTZ, son: La Calizzanesa, La Cruz, La Emiliana, La Pastería, La Princesa, La Sin Rival y Salerno. Cada una de ellas realiza la producción en sus respectivas plantas con la misma fórmula y control de calidad a efectos de obtener un producto uniforme y, como están ubicadas en diferentes zonas de Montevideo, logran a través de este sistema una mejor cobertura espacial del mercado. Además, pueden abaratar costos al comprar mayores volúmenes de materia prima y realizar publicidad en forma conjunta. El objetivo de este emprendimiento es ofrecer pastas artesanales a los supermercados con precios competitivos. Actualmente están abasteciendo a las cadenas Multiahorro, Superfresco y Ta-Ta. Según Mónica Calvar, directora de 
La Sin Rival, "las ventas del grupo Vera Pasta a estas grandes superficies se cobran entre los 30 y 45 días, es decir que se opera dentro de los parámetros habituales del comercio". 29

\subsubsection{Canales de distribución}

Los canales de comercialización son diferentes para los distintos tipos de productos.

En general, existen dos grandes etapas en la comercialización:

La etapa mayorista, integrada por importadores y distribuidores -frecuentemente son las mismas firmas-.

La etapa minorista. En los últimos años en el Uruguay, así como en otros países, se han desarrollado exitosamente nuevas modalidades de comercialización minorista, desplazando a las tradicionales. Entre estas modalidades en expansión se encuentran:

Cadenas de supermercados (alimentación, higiene personal y del hogar, varios) Shoppings Centers (vestimenta, electrodomésticos, tocador, librería, servicios, varios)

Asimismo, se están expandiendo sistemas de venta directa, telemarketing y otras modalidades de comercialización.

En la comercialización de máquinas e insumos agropecuarios existe una red de cooperativas de productores agropecuarios, que realiza compras mayoristas y vende a los productores.

Por las características del Uruguay se pueden distinguir dos mercados diferenciados:

Montevideo: con más del $40 \%$ de la población nacional, es un mercado concentrado geográficamente y con un nivel adquisitivo mayor al del resto del país.

Los estratos de consumidores de ingresos medios y altos están relativamente más representados en la capital que en el Interior del país.

\footnotetext{
${ }^{29}$ http://www.elpais.com.uy/Suple/EconomiaYMercado/04/09/16/ecoymer 111264.asp extraído el 10 de Enero de 2013
} 
Interior del país: Es un mercado disperso y con un nivel adquisitivo menor.

Sin embargo, existen algunas localizaciones del Interior que, por su población y sus niveles de ingresos, pueden constituir un mercado atractivo, entre otras:

-Departamento de Canelones, en particular la zona de influencia de Montevideo (Costa de Oro, Las Piedras, Pando, etc.)

-Departamento de Maldonado (ciudades de Punta del Este, Piriápolis , Maldonado)

\section{-Departamento de Colonia}

-Departamento de Paysandú.

Algunas redes de comercialización se extienden a todo el país o a las zonas más densamente pobladas. Otras, en cambio, se concentran sólo en Montevideo. ${ }^{30}$

${ }^{30} \mathrm{http}: / /$ www.argentinatradenet.gov.ar/sitio/mercado/material/GUIA NEGOCIOS 2012.pdf 


\section{ESQUEMA DE IMPLEMENTACIÓN DEL PLAN}

Luego de analizar las diferentes variables que conforman el estudio del presente trabajo, estableceremos el precio de exportación, los aspectos logísticos, las condiciones de venta, la comercialización en el mercado destino y el resultado económico proyectado.

El plan de exportación se pondrá en acción después de los primeros seis meses de puesta en marcha del plan de exportación.

Se considera la venta de una máquina cada dos meses, donde podrá atender el mercado destino sin descuidar las ventas locales.

El objetivo inicial será el de captar una participación del $10 \%$ del mercado meta conformado por 130 fábricas de pastas localizadas en Montevideo, capital del Uruguay.

Para iniciar las operaciones de comercialización se contactará un agente de ventas especializado en máquinas para la industria de la pasta fresca .

Se establecerá un contrato de agente de ventas, donde se estipularán varios puntos a tener en cuenta: duración, plaza, comisión, producto a ser comercializado, aspectos legales, derechos y obligaciones. ${ }^{31}$

A los efectos de reducir al máximo posible riesgos por incumplimiento de pago el instrumento que será negociado en función a la recepción de la orden de compra y el contrato de compra venta internacional, será la carta de crédito (L/C).

La misma establecerá un plazo de 90 días desde la fecha de embarque para ser cancelada por el importador.

El incoterm a ser utilizado será el costo y flete, siendo su sigla para el medio de transporte seleccionado el CPT (carriage paid to ) punto de destino .

De esta manera la empresa tendrá la opción de coordinar los embarques y controlar el proceso logístico y además obtener una mejor negociación de las tarifas de flete internacional.

\subsection{Definición del precio de exportación}

En este punto analizaremos el precio de exportación, considerando los costos

${ }^{31}$ Ver Anexo Modelo de Contrato de Agente de Ventas www.aduanargentina.com 
fijos y variables, derechos de exportación, reintegros, utilidad y se definirá la comisión del agente de ventas en un $5 \%$ del valor FOB .

Los cálculos se basan en información suministrada por los socios gerentes en las entrevistas realizadas.

Cuadro 6 :Cálculo del precio de exportación

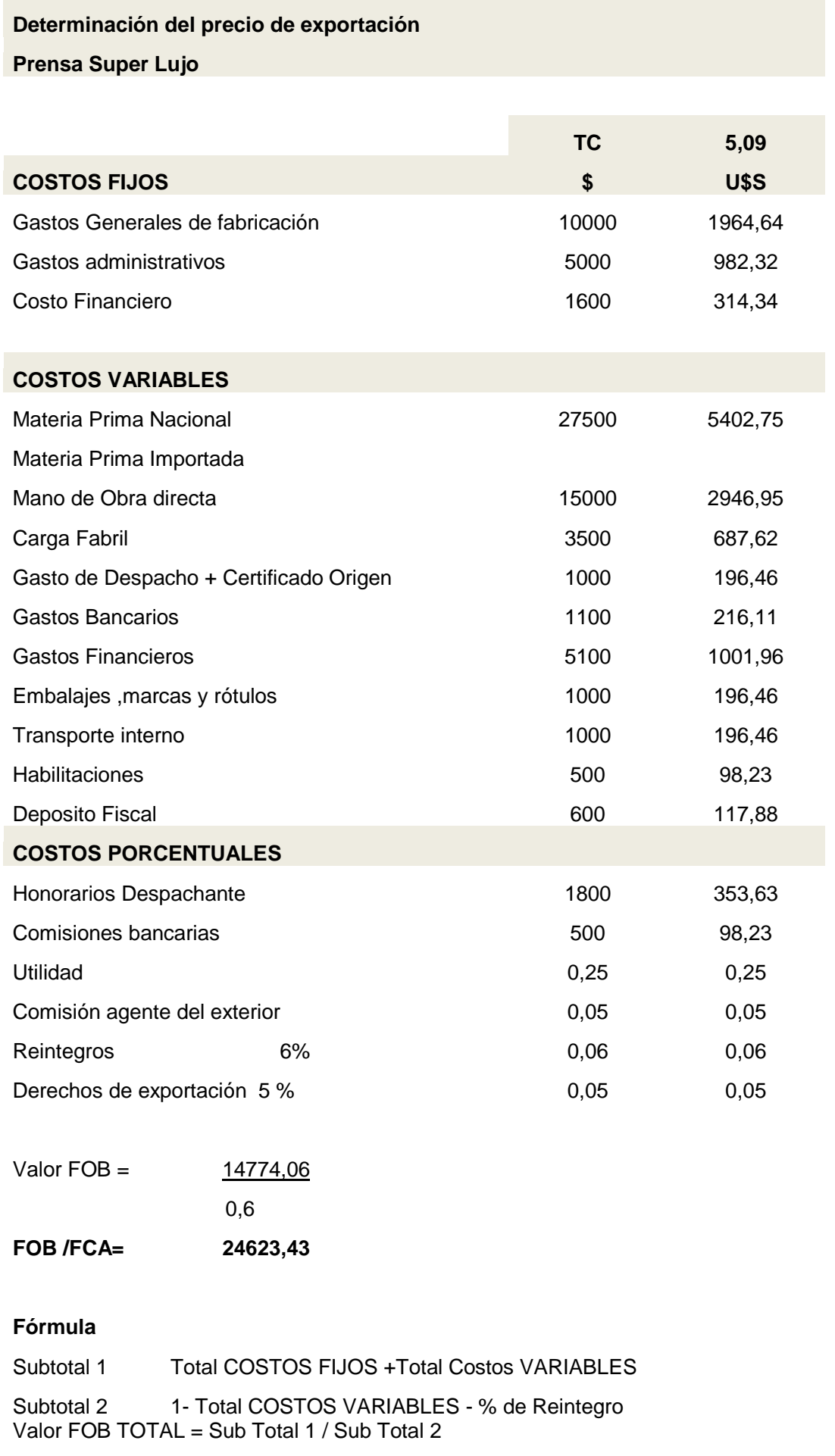


A partir del valor FOB/FCA resultante de la planilla de cálculo incluiremos en el precio de venta el costo del medio de transporte a ser utilizado.

\subsection{Aspectos logísticos}

Teniendo en cuenta las medidas y pesos del equipo, consideramos los diferentes medios de transporte posibles comparando tarifas y tiempos de lead time, resultando el más conveniente la vía aérea. Tanto el transporte terrestre como el lacustre implican la utilización de depósitos fiscales en zona primaria aduanera haciendo encarecer el precio final del flete para este producto.

Cuadro 7 :Cálculo Flete vía aérea Buenos Aires - Montevideo

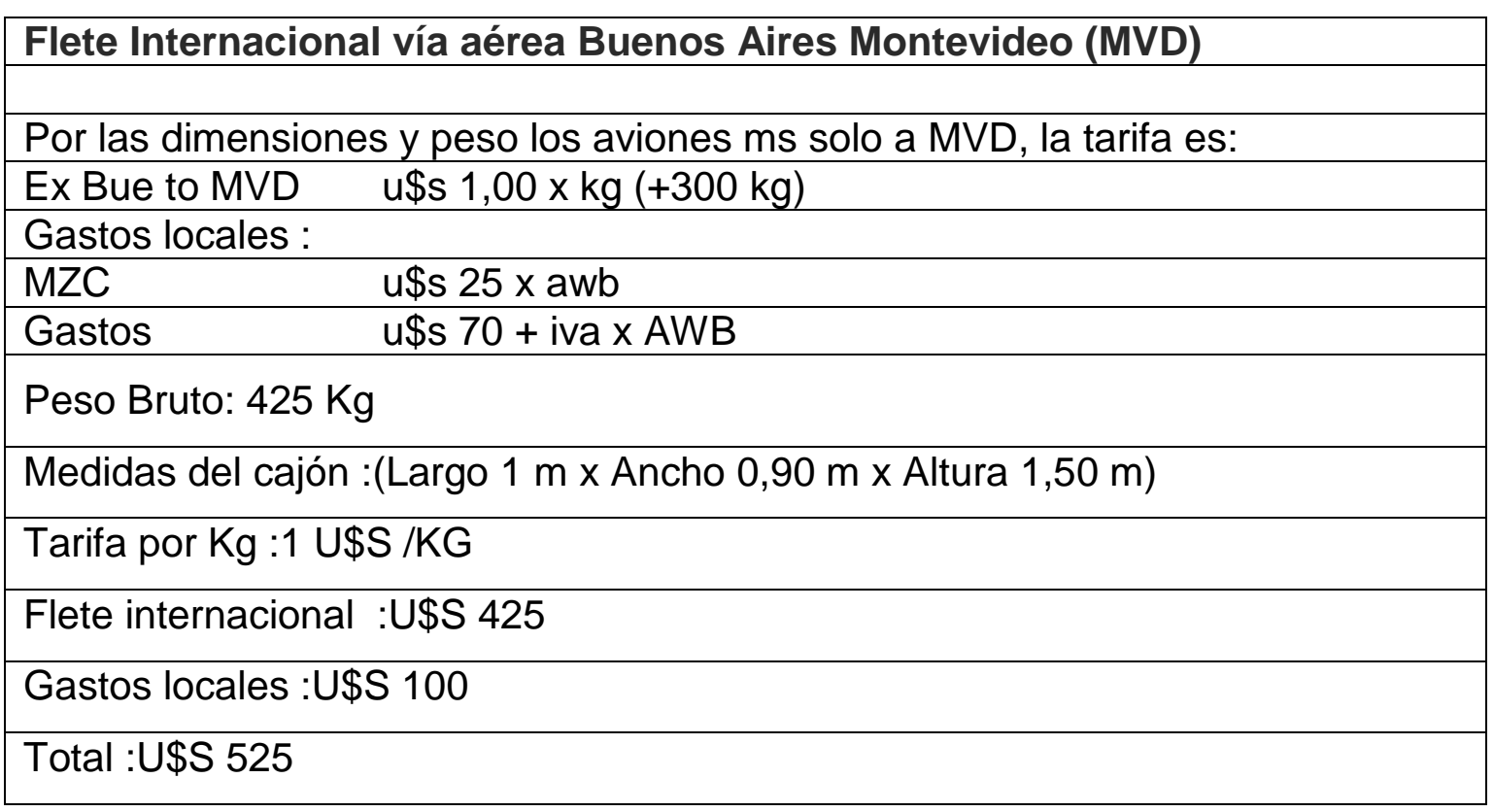

Fuente :Cotización Urban Cargo S.R.L

De esta manera el precio CPT Montevideo sería U\$S 25148,43 .

\subsection{Promoción}

Una de las opciones para realizar promoción de productos es a través de misiones comerciales empresariales sectoriales, tanto grupales como individuales, a partir de agendas de negocios concertadas por la Sección Comercial de la Embajada Argentina, con contrapartes uruguayas. 
Si bien no existe un calendario oficial de ferias y exposiciones a realizarse en este país, la participación en ferias y exposiciones temáticas o de carácter general (industrial y/o comercial) también constituye un polo de atracción para la promoción de productos. ${ }^{32}$

En tal sentido, la Embajada Argentina en Uruguay auspicia la participación de empresas argentinas en la Exposición Internacional de Ganadería, Muestra Agroindustrial y Comercial, que se realiza en el mes de septiembre en Montevideo, organizada por la Asociación Rural del Uruguay y que durante los 12 días de duración atrae una gran cantidad de visitantes que supera el medio millón de personas.

\subsection{Resultado económico proyectado}

El plan de negocios se realizará con un horizonte de cinco años .En el siguiente cuadro se analizará el resultado económico de acuerdo a las ventas previstas sin considerar equipos adicionales y productos complementarios.

Cuadro 8 : Proyección de resultados

\begin{tabular}{|c|c|c|c|c|c|c|}
\hline & Año 1 & Año 2 & Año 3 & Año 4 & Año 5 & Total \\
\hline Ventas U\$S & 75444,39 & 150888,78 & 150888,78 & 150888,78 & 150888,78 & 678999,51 \\
Flete & -1575 & -3150 & -3150 & -3150 & -3150 & \\
FOB/FCA & 73869,39 & 147738,78 & 147738,78 & 147738,78 & 147738,78 & 664824,51 \\
\cline { 5 - 7 } Utilidad & 18467,35 & 36934,70 & 36934,70 & 36934,70 & 36934,70 & $\mathbf{1 6 6 2 0 6 , 1 5}$ \\
\hline
\end{tabular}

Si consideramos la inversión al inicio del proyecto (U\$S50.000) y que las ventas estimadas proyectadas a 5 años totalizan (U\$ 678.999,51) y se deduce el valor del flete (U\$ 14.175), obtenemos el precio FOB/FCA total de venta (U\$S $664.824,51$ ), sobre este valor aplicamos el margen de utilidad del $25 \%$ (U\$S $166.206,15)$,determinamos que el resultado del plan de negocios fue positivo totalizando en (U\$ 116206,15) .

\footnotetext{
${ }^{32}$ www.argentinatradenet.gov.ar ( Ver Ferias - Uruguay)
} 
La inversión inicial es recuperada en el segundo año de acuerdo a las proyecciones realizadas.

\section{CONCLUSIONES}

Luego de analizar las variables que resultan del presente trabajo de investigación podemos enunciar las principales conclusiones:

-Tanto los socios gerentes como su personal, frente al desafío de iniciar un plan de negocios de exportación se ven motivados y consideran que realizándolo en forma gradual adquirirán experiencia en los negocios internacionales.

-La implementación del plan será llevado a cabo a partir del sexto mes de iniciado el proyecto.

- La capacidad productiva si bien es acotada a partir de la compra de un centro de mecanizado, podrá atender el mercado destino sin descuidar las ventas locales, considerando una inversión inicial relativamente baja.

-La inversión del proyecto será conformado con capital propio.

-La estructura organizacional actual está enfocada a las necesidades del mercado doméstico, siendo recomendable la contratación, en forma externa, de un asesor en Marketing Internacional.

-El producto objeto de la comercialización resulta atractivo frente a la oferta de la competencia internacional, teniendo en cuenta la funcionalidad y el precio.

-El régimen de exportación vigente no requiere de intervenciones previas.

-Para identificar los mercados potenciales alternativos se seleccionaron tres países integrantes del Mercosur, considerando las ventajas económicas ,logísticas y geográficas como una fortaleza del proyecto.

-El país destino no presenta barreras de ingreso para la importación, tanto en los aspectos, legales como en los logísticos.

-Los aranceles de importación son del $0 \%$ frente al $14 \%$ de productos originarios de países que no integran el Mercosur.

-El mecanismo de ingreso en el mercado destino será a través de un agente de ventas especializado en el rubro .Las ventas se realizarán en forma directa a clientes finales importadores. 
-El mercado destino seleccionado es la ciudad de Montevideo capital de Uruguay, está conformado por 130 fábricas de elaboración de pasta fresca, del cual se pretende tener una participación del $10 \%$ en el mismo.

-El plan de ventas, considerando la estructura y la capacidad productiva se estima en 1 máquina cada dos meses. En el primer año, totalizarán 3 máquinas y para los siguientes años 6 máquinas anuales.

-Posteriormente se estima poder anexar productos complementarios del portfolio de productos (Ralladoras y picadoras individuales, amasadoras auxiliares, amasadoras térmicas, matrices para prensas, accesorios de máquinas).

-La promoción de las ventas estará llevada a cabo por el agente de ventas y complementada con la participación en misiones comerciales y ferias internacionales.

-El resultado proyectado es positivo, y se estima el recupero de la inversión en el segundo año. 


\section{BIBLOGRAFÍA}

ALEKSINK ,NESTOR y SEGRÉ GUSTAVO -Fundamentos para un proyecto de exportación -2012 2ª Edición Ed.Osmar D.Buyatti

BALANKO,GREG Como preparar un exitoso plan de negocio -2008-Ed.Mc Graw Hill

BOTTA ,MIRTA Tesis, monografías e informes.Nuevas normas y técnicas de investigación y redacción -1ㄹed.-Buenos Aires :Biblos ,2002

BRADLEY,FRANK Marketing Internacional $5^{\circ}$ Edicion -Ed.Pearson ,Prentice Hall

CIGNACO ,B.Fundamentos de comercialización internacional Pymes-

Ed.Macchi

ECO,UMBERTO, Como se hace una Tesis Ed.Gedisa

PARIS ,JOSÉ ANTONIO Marketing Internacional desde la óptica

latinoamericana $1^{\circ}$ Edición -Errepar

WILENSKY ,ALBERTO Claves de la estrategia competitiva Fundación Osde

\section{OTRAS FUENTES}

Documentos de Internet

Secretaría de la Pequeña y Mediana Empresa y Desarrollo Regional http://www.sepyme.gob.ar

Nomenclador Común del Mercosur http://www.aduanaargentina.com/nc.php

Mercado Único de Divisas Res. MEFP 231/12 Res. MEFP 142/12 www.pcram.net

ABIMA - Asociación Brasileña de Industrias de Masas Alimenticias http://www.abima.com.br/estMercNacMassas.asp

International Pasta Organisation http://www.internationalpasta.org

http://www.equipos.com.uy

Cámara Uruguaya de Fabricantes de Pastas www.pasterosuruguayos.com 
Aiera Asociación de importadores y Exportadores de la República Argentina www.aiera.org

Fabricantes de máquinas italianas Dominioni Punto \& Pasta www.dominioni.it Cámara Nacional de Comercio y Servicios del Uruguay www.cncs.com.uy Administración nacional de puertos República Oriental del Uruguay www.anp.com.uy

Parlamento del Uruguay www.parlamento.gub.uy

Promoción de inversiones y exportaciones www.uruguayxxi.gub.uy

Información de Uruguay www.infouruguay.com.uy

Intendencia de Montevideo www.montevideo.gob.uy

Modelo de Contrato de Agente de Ventas www.aduanargentina.com

Ministerio de Relaciones Exteriores, Comercio Internacional y Culto de la

República Argentina www.argentinatradenet.gov.ar Ferias -Uruguay

http://www.elpais.com.uy/Suple/EconomiaYMercado/04/09/16/ecoymer 111264.a

$\underline{\mathrm{sp}}$

Apuntes de cátedra de diversas asignaturas del Postgrado de Marketing Internacional -UNLP

Fuentes verbales :

Los socios de D'alessio y empleados mediante entrevistas personales aportaron información sobre la situación actual de la empresa. 


\section{ANEXOS}

\begin{tabular}{|c|c|c|c|c|c|c|}
\hline Departamento & Capital & Población & rcentaje & Superficie & Porcentaje & Densidad \\
\hline Montevideo & Montevideo & 1.325 .968 & $40,91 \%$ & $530 \mathrm{~km}^{2}$ & $0,30 \%$ & $2.523 \mathrm{hab} . / \mathrm{km}^{2}$ \\
\hline Canelones & Canelones & 485.240 & $14,97 \%$ & $4.536 \mathrm{~km}^{2}$ & $2,59 \%$ & $106,98 \mathrm{hab} . / \mathrm{km}^{2}$ \\
\hline Maldonado & Maldonado & 140.192 & $4,33 \%$ & $4.793 \mathrm{~km}^{2}$ & $2,74 \%$ & 29,25 hab. $/ \mathrm{km}^{2}$ \\
\hline Salto & Salto & 123.120 & $3,80 \%$ & $14.163 \mathrm{~km}^{2}$ & $8,09 \%$ & $8,69 \mathrm{hab} . / \mathrm{km}^{2}$ \\
\hline Colonia & Colonia del Sacramento & 119.266 & $3,68 \%$ & $6.106 \mathrm{~km}^{2}$ & $3,49 \%$ & 19,53 hab./km² \\
\hline Paysandú & Paysandú & 113.244 & $3,49 \%$ & $13.922 \mathrm{~km}^{2}$ & $7,95 \%$ & $8,13 \mathrm{hab} . / \mathrm{km}^{2}$ \\
\hline Rivera & Rivera & 104.921 & $3,24 \%$ & $9.370 \mathrm{~km}^{2}$ & $5,35 \%$ & 11,20 hab. $/ \mathrm{km}^{2}$ \\
\hline San José & $\underline{\text { San José de Mayo }}$ & 103.104 & $3,18 \%$ & $4.992 \mathrm{~km}^{2}$ & $2,85 \%$ & 20,65 hab. $/ \mathrm{km}^{2}$ \\
\hline Tacuarembó & Tacuarembó & 90.489 & $2,79 \%$ & $15.438 \mathrm{~km}^{2}$ & $8,82 \%$ & 5,86 hab. $/ \mathrm{km}^{2}$ \\
\hline Cerro Largo & $\underline{\text { Melo }}$ & 86.564 & $2,67 \%$ & $13.648 \mathrm{~km}^{2}$ & $7,80 \%$ & 6,34 hab. $/ \mathrm{km}^{2}$ \\
\hline Soriano & Mercedes & 84.563 & $2,61 \%$ & $9.008 \mathrm{~km}^{2}$ & $5,15 \%$ & $9,39 \mathrm{hab} . / \mathrm{km}^{2}$ \\
\hline Artigas & $\underline{\text { Artigas }}$ & 78.019 & $2,41 \%$ & $11.928 \mathrm{~km}^{2}$ & $6,82 \%$ & 6,42 hab. $/ \mathrm{km}^{2}$ \\
\hline Rocha & Rocha & 69.937 & $2,16 \%$ & $10.551 \mathrm{~km}^{2}$ & $6,03 \%$ & $6,63 \mathrm{hab} . / \mathrm{km}^{2}$ \\
\hline Florida & Florida & 68.181 & $2,10 \%$ & $10.417 \mathrm{~km}^{2}$ & $5,95 \%$ & 6,56 hab. $/ \mathrm{km}^{2}$ \\
\hline Lavalleja & $\underline{\text { Minas }}$ & 60.925 & $1,88 \%$ & $10.016 \mathrm{~km}^{2}$ & $5,72 \%$ & 6,08 hab. $/ \mathrm{km}^{2}$ \\
\hline Durazno & Durazno & 58.859 & $1,82 \%$ & $11.643 \mathrm{~km}^{2}$ & $6,65 \%$ & $5,06 \mathrm{hab} . / \mathrm{km}^{2}$ \\
\hline$\underline{\text { Río Negro }}$ & Fray Bentos & 53.989 & $1,67 \%$ & $9.282 \mathrm{~km}^{2}$ & $5,30 \%$ & 5,82 hab. $/ \mathrm{km}^{2}$ \\
\hline$\underline{\text { Treinta y Tres }}$ & $\underline{\text { Treinta y Tres }}$ & 49.318 & $1,52 \%$ & $9.529 \mathrm{~km}^{2}$ & $5,44 \%$ & $5,18 \mathrm{hab} . / \mathrm{km}^{2}$ \\
\hline Flores & $\underline{\text { Trinidad }}$ & 25.104 & $0,77 \%$ & $5.144 \mathrm{~km}^{2}$ & $2,94 \%$ & 4,88 hab. $/ \mathrm{km}^{2}$ \\
\hline Total & & 3.241 .003 & $100 \%$ & $175.016 \mathrm{~km}^{2}$ & $100 \%$ & 19 hab./km² \\
\hline
\end{tabular}

Fuente : Instituto Nacional de Estadística INE URUGUAY http://www.ine.gub.uy 
Anexo 2 :Consumo de pasta per capita por país en el $2011(\mathrm{~kg})$

\begin{tabular}{|c|c|c|c|}
\hline Italy & 26.0 & Spain & 5.0 \\
\hline Venezuela & 12.3 & Slovak Republic & 5.0 \\
\hline Tunisia & 11.9 & Bolivia & 4.8 \\
\hline Greece & 10.5 & Netherlands & 4.4 \\
\hline Switzerland & 9.3 & Lituania & 4.4 \\
\hline Sweden & 9.0 & Poland & 4.4 \\
\hline United States & 8.8 & Latvia & 4.1 \\
\hline Iran & 8.5 & Dominican Rep. & 4.0 \\
\hline Chile & 8.4 & Australia & 4.0 \\
\hline Peru & 8.2 & Israel & 4.0 \\
\hline France & 8.1 & Ecuador & 3.9 \\
\hline Germany & 8.1 & Panama & 3.8 \\
\hline Argentina & 7.9 & Costa Rica & 3.2 \\
\hline Russia & 7.8 & Finland & 3.2 \\
\hline Hungary & 7.5 & Colombia & 3.0 \\
\hline Uruguay & 7.5 & Mexico & 2.7 \\
\hline Croazia & 7.3 & Romania & 2.7 \\
\hline Austria & 7.0 & United Kingdom & 2.5 \\
\hline Slovenia & 6.7 & Guatemala & 2.0 \\
\hline Portugal & 6.6 & Denmark & 2.0 \\
\hline Canada & 6.5 & Libya & 2.0 \\
\hline Brazil & 6.2 & Japan & 1.7 \\
\hline Turkey & 6.1 & Egypt & 1.2 \\
\hline Czech Republic & 6.0 & Ireland & 1.0 \\
\hline Belgium - Lux. & 5.4 & EI Salvador & 1.0 \\
\hline Estonia & 5.3 & & \\
\hline
\end{tabular}


Anexo 3 : Modelo de contrato de Agente de Ventas

CONTRATO hecho el día $\begin{gathered}\text { de } \\ \text { con domicilio comercial del } 200 \text { establecido entre }\end{gathered}$ ( de aquí en adelante denominado "el Mandante"),

por un lado, y ( de aquí en adelante denominado "el

Agente"), por el otro.

\section{POR EL CUAL SE HA CONVENIDO LO SIGUIENTE :}

1. El Mandante nombra al Agente, quién, como tal y desde (fecha) será su único representante en ( de aquí en adelante denominado "la zona") para la venta de de fabricación del Mandante y todos aquellos otros bienes y mercancías (todos los cuales se denominarán de aquí en adelante "los productos"), según convenga más adelante entre ellos.

2. El agente, por una duración de años ( $y$ en adelante hasta la fecha que convengan de común acuerdo por escrito con preaviso de meses) prestará al Mandante con diligencia y buena fe servicios en calidad de representante suyo y pondrá su empeño en ampliar la venta de los productos del Mandante dentro de la zona de su representación y no hará nada que pueda entorpecer tal venta o crear obstáculos al desenvolvimiento de los negocios del Mandante en dicha zona comercial.

3. El Mandante pondrá a disposición del Agente, en tiempo oportuno, una manifestación en la que indique los precios mínimos a los cuales los productos tendrán que ser individualmente puestos en venta, y el Agente no podrá ponerlos en venta a precios inferiores a los especificados en la manifestación del Mandante, sin perjuicio de tratar, en cada caso, de venderlos al mejor precio que le sea posible obtener.

4. El Agente no podrá vender ninguno de los productos del Mandante a persona o compañía o firma alguna, con residencia fuera de su zona de representación con vistas a la reexportación a ningún otro país o zona sin el consentimiento por escrito del Mandante.

5. En el transcurso de su representación, el Agente designado en este contrato no tomará a su cargo la venta de productos de clase similar o que puedan competir o crear obstáculos a la venta de los productos del Mandante, sea por cuenta propia, sea de parte de otra persona, compañía o firma cualquiera.

6. Al recibo de toda orden de compra de los productos del Mandante, el Agente deberá transmitirle sin tardanza tal orden de compra y (si la orden de compra es aceptada por el Mandante) la ejecutará, suministrando los productos directamente al cliente. 
7. Una vez ejecutada cualquier orden de compra, el Mandante enviará al Agente copia duplicada de la factura remitida al cliente junto con los productos a que corresponda y del mismo modo le enviará en tiempo oportuno noticia del pago efectuado por el cliente al Mandante.

8. El Agente llevará en debida forma la contabilidad de todas las órdenes de compra que haya obtenido y cada meses remitirá al Mandante un estado de dicha contabilidad.

9. El Mandante reconocerá al Agente las siguientes comisiones ( basadas en precios F.O.B. España) por todas las órdenes de compra obtenidas por el Agente en la zona y ejecutadas por el Mandante. Queda dicho que las comisiones correspondientes a los cobros a los clientes efectivamente efectuados por el Mandante serán abonadas trimestralmente por éste al Agente.

10. El Agente tendrá derecho a comisión en los términos y condiciones especificados en el párrafo precedente sobre todas las órdenes de exportación que el Mandante reciba.

11. En caso de diferencia acerca de la cuantía que a título de comisión el Mandante debe pagar al Agente, tal diferencia ha de ser solucionada por los Auditores del Mandante en el momento de producirse. Su decisión será obligatoria, así para el Mandante, como para el Agente.

12. El Agente no ha de comprometer en modo alguno el crédito del Mandante.

13. El Agente no emitirá garantía alguna en relación con los productos tratados sin autorización por escrito del Mandante.

14. El Agente no recibirá pagos de los clientes sin la autorización del Mandante.

15. El Agente no abrirá crédito, ni negociará con persona, compañía o firma alguna, con las cuales el Mandante le haya dado instrucciones en tiempo oportuno de no operar a crédito ni negociar.

16. El Mandante tendrá derecho a rehusarse a ejecutar o a recibir una orden cualquiera, o parte de ella, obtenida por el Agente, y el Agente no podrá reclamar comisión sobre cualquier orden, o parte de ella, rehusada en ejercicio de tal derecho.

17. Toda cuestión o diferencia, sea cual fuere, que pueda surgir en cualquier momento en adelante entre las partes de este contrato, o entre sus respectivos representantes, en relación con las cláusulas presentes, o con el objeto de las mismas, o que de ellas se deriven, o con ellas se relacionen o acerca de como debe interpretarse, o por cualquier otra razón, será sometida a arbitraje en la República Argentina. 
18. La interpretación de este contrato se entenderá en todos sus aspectos con sujeción a la ley Argentina.

EN TESTIMONIO DE LO CUAL, las partes concluyen este contrato, en fecha y año previamente indicados.

Firmas

Fuente : www.aduanaargentina.com Modelo de contrato de Agente de Ventas

Anexo 4 Costos Internos en Uruguay

Anticipo de IVA 10\%

IVA tasa básica $22 \%$

Extraordinario es dependiendo al valor en aduana (CIF) es una escala que va desde U\$S 12 hasta U\$S 600.

Tasa consular $2 \%$

Modalidad Terrestre:

Origen: Argentina

Destino: Montevideo

Frontera de Cruce: Colonia

NCM: 8438.10.00

Valor CIF aproximado: U\$S 25000.00

Peso: $400 \mathrm{~kg}$ aprox.

T.S.A $\$ 900,00$

Extraordinario $\$ 2249,00$

IVA $\$ 99005,00$

Anticipo de IVA $\$ 45002,00$

Guías de tránsito $\$ 226,00$

ANP $\$ 300,00$

Comunicaciones DNA Impresión DUA $\$ 150,00+$ iva Gastos de Despacho $\$ 450,00+$ iva Honorarios $\$ 2400,00+$ iva $\$ 5500,00+i v a$

Fuente : www.argentinatradenet.gov.ar , MTM Logistics S.R.L 
Modalidad Maritimo:

Origen: Argentina

Destino: Montevideo

NCM: 8438.10.00

Valor CIF: U\$S 22620.00

Peso: 400 kg aprox.

T.S.A

$\$ 900,00$

Extraordinario

$\$ 2249,00$

IVA

$\$ 99005,00$

Anticipo de IVA

$\$ 45002,00$

Guías de tránsito

$\$ 226,00$

ANP

$\$ 9331,00$

Terminal Portuaria

$\$ 4500,00$ aprox

Comunicaciones DNA $\$ 450,00+$ iva

Impresión DUA $\$ 450,00+$ iva

Gastos de Despacho

$\$ 2400,00+$ iva

Honorarios

$\$ 5500,00+$ iva

Cotización expresada en Pesos Uruguayos.

Fuente : www.argentinatradenet.gov.ar, MTM Logistics S.R.L 


\section{ACLARACIÓN}

"Declaro bajo juramento que esta tesis fue elaborada por mí, que no utilicé ningún otro material que no haya dado a conocer en las referencias y que no utilicé frases o párrafos de otros autores y que este trabajo de tesis nunca ha sido presentado ante un comité de evaluación de tesis y que no transgrede derechos de terceros."

Firma

Aclaración

Número de documento 